\title{
Cirripectes matatakaro, a new species of combtooth blenny from the Central Pacific, illuminates the origins of the Hawaiian fish fauna
}

\author{
Mykle L Hoban $^{\text {Corresp., } 1}$, Jeffrey T Williams ${ }^{2}$ \\ ${ }^{1}$ Hawai'i Institute of Marine Biology, University of Hawai'i at Mānoa, Kāne'ohe, Hawai'i, United States \\ 2 Division of Fishes, Department of Vertebrate Zoology, National Museum of Natural History, Smithsonian Institution, Washington, District of Columbia, \\ United States \\ Corresponding Author: Mykle L Hoban \\ Email address: mhoban@hawaii.edu
}

Included among the currently recognized 23 species of combtooth blennies of the genus Cirripectes (Blenniiformes: Blenniidae) of the Indo-Pacific are the Hawaiian endemic $C$. vanderbilti, and the widespread $C$. variolosus. During the course of a phylogeographic study of these species, a third species was detected, herein described as $C$. matatakaro. The new species is distinguished primarily by the configuration of the pore structures posterior to the lateral centers of the transverse row of nuchal cirri in addition to 12 meristic characters and nine morphometric characters documented across 72 specimens and $\sim 4.2 \%$ divergence in mtDNA cytochrome oxidase subunit $\mathrm{I}$. The new species is currently known only from the Marquesas, Gambier, Pitcairns, Tuamotus, and Australs in the South Pacific, and the Northern Line Islands and possibly Johnston Atoll south of Hawai'i. Previous researchers speculated that the geographically widespread $C$. variolosus was included in an unresolved trichotomy with the Hawaiian endemic and other species based on a morphological phylogeny. Our molecular-phylogenetic analysis resolves many of the previously unresolved relationships within the genus and reveals $C$. matatakaro as the sister lineage to the Hawaiian $C$. vanderbilti. The restricted geographic distribution of Cirripectes matatakaro combines with its status as sister to $C$. vanderbilti to indicate a southern pathway of colonization into Hawai'i. 


\section{Cirripectes matatakaro, a new species of combtooth}

2 blenny from the Central Pacific, illuminates the origins

3 of the Hawaiian fish fauna

4

5 Mykle L Hoban ${ }^{1}$, Jeffrey T Williams ${ }^{2}$

6

$7 \quad{ }^{1}$ Hawai'i Institute of Marine Biology, University of Hawai'i at Mānoa, Kāne'ohe, HI, USA

$8{ }^{2}$ Division of Fishes, Department of Vertebrate Zoology, National Museum of Natural History,

9 Smithsonian Institution, Washington, DC, USA

10

11 Corresponding Author:

12 Mykle L Hoban ${ }^{1}$

13 46-007 Lilipuna Rd, Kāne 'ohe, HI, USA

14 Email address: mh@myklehoban.com 
16

17

18

19

20

21

22

23

24

25

26

27

28

29

30

31

32

33

34

35

36

37

38

39

40

41

42

43

44

45

46

47

48

49

50

51

52

53

54

55

\section{Abstract}

Included among the currently recognized 23 species of combtooth blennies of the genus Cirripectes (Blenniiformes: Blenniidae) of the Indo-Pacific are the Hawaiian endemic $C$. vanderbilti, and the widespread $C$. variolosus. During the course of a phylogeographic study of these species, a third species was detected, herein described as $C$. matatakaro. The new species is distinguished primarily by the configuration of the pore structures posterior to the lateral centers of the transverse row of nuchal cirri in addition to 12 meristic characters and nine morphometric characters documented across 72 specimens and $4.2 \%$ divergence in mtDNA cytochrome oxidase subunit I. The new species is currently known only from the Marquesas, Gambier, Pitcairns, Tuamotus, and Australs in the South Pacific, and the Northern Line Islands and possibly Johnston Atoll south of Hawai'i. Previous researchers speculated that the geographically widespread $C$. variolosus was included in an unresolved trichotomy with the Hawaiian endemic and other species based on a morphological phylogeny. Our molecularphylogenetic analysis resolves many of the previously unresolved relationships within the genus and reveals $C$. matatakaro as the sister lineage to the Hawaiian $C$. vanderbilti. The restricted geographic distribution of Cirripectes matatakaro combines with its status as sister to $C$. vanderbilti to indicate a southern pathway of colonization into Hawai' $i$.

\section{Introduction}

The Hawaiian Archipelago is one of the most isolated island groups in the world, constituting its own marine biogeographic province (Briggs \& Bowen, 2012). As a result of this isolation, a high rate of endemism is found among the marine fauna of Hawai' $\mathrm{i}$, with the proportion of endemism among marine fishes recorded at 25\% (Randall, 2007) in the Main Hawaiian Islands and considerably higher on mesophotic reefs in the remote Northwest Hawaiian Islands (Kane, Kosaki \& Wagner, 2014; Kosaki et al., 2016). By biomass and numeric density, endemic species may comprise $32-50 \%$ of fish assemblages on Hawaiian reefs, respectively (DeMartini \& Friedlander, 2004). Due to the volcanic origin of the archipelago, all shallow coral reef species in Hawai' $i$ must by necessity originate elsewhere. Two prevailing hypotheses have been presented for the origins of Hawaiian reef species. Hourigan and Reese (1987) proposed that Hawaiian inshore fishes primarily originate in the western Pacific, with the closest faunal affinities found in the Ryukyu Islands and southern Japan. They suggested that rare dispersal events of IndoPacific species via the Kuroshio Current to the Northwest Hawaiian Islands are the most likely source of fish diversity in the archipelago. Gosline (1955) hypothesized that Hawaiian species originate from the south, via "stepping stone" dispersal through the Line Islands, with Johnston Atoll occupying a key position between the Hawaiian and Northern Line islands.

Phylogeographic studies provide evidence that species such as limpets (Cellana spp.), butterflyfishes (Chaetodon miliaris, C. fremblii), and the deepwater snapper Pristipomoides filamentosus colonized from the Western Pacific (Craig, Eble \& Bowen, 2010; Bird et al., 2011; Gaither et al., 2011) and the surgeonfishes Acanthurus nigroris and A. olivaceus and Etelis spp. snappers colonized via the southern route (DiBattista et al., 2010; Andrews et al., 2014; Gaither 
56

57

58

59

60

61

62

63

64

65

66

67

68

69

70

71

72

73

74

75

76

77

78

79

80

81

82

83

84

85

86

87

88

89

90

91

92

93

94

95

et al., 2015). It is apparent that there is not a single geographical origin of reef species in Hawai $i$, but rather that taxa arrived at different times from both hypothesized origins (Hodge, Herwerden \& Bellwood, 2014).

To date, studies examining the origins of Hawaiian reef fauna have focused primarily on conspicuous, larger-bodied species. Cryptobenthic reef fishes, as defined by Brandl et al. (2018), are families with more than $10 \%$ of species smaller than $50 \mathrm{~mm}$, and comprise families such as combtooth blennies (Blenniidae), gobies (Gobiidae), triplefins (Tripterygiidae), and cardinalfishes (Apogonidae), among others. Despite constituting a relatively small fraction of reef biomass, they contribute disproportionately to coral reef food webs through abundant larval supply and high predation mortality (Brandl et al., 2019). These fishes make up a large part of the taxonomic diversity found on reefs and can exhibit high endemism (Brandl et al., 2018). Hawai'i has 14 recognized combtooth blenny species, of which eight are endemic (Randall, 2007). As in other families, endemic Hawaiian blenny species often have sister taxa that are widespread in the Indo-Pacific (Randall, 1998).

The genus Cirripectes Swainson (Blenniiformes: Blenniidae) comprises 23 recognized species of combtooth blennies broadly distributed in the Indo-Pacific from East Africa to Rapa Nui (Easter Island) (Williams, 1988; Delrieu-Trottin et al., 2018). They are small (majority $<100 \mathrm{~mm} \mathrm{SL}$ ) herbivorous fishes that primarily inhabit rocky or coral substrate in shallow $(<5 \mathrm{~m})$ high surge forereef habitat (Williams, 1988). Species in the genus show considerable variation in geographic range size, from small area endemism (e.g. C. heemstraorum) to Indo-Pacific-wide distribution (e.g. C. quagga) (Williams, 1988; 2010). Cirripectes is most closely related to Ophioblennius Gill, Scartichthys Jordan \& Evermann, and Exallias Jordan \& Evermann (Williamsichthys clade), with which they share an ophioblennius-type larval stage having pairs of large recurved canines anteriorly on premaxillary and dentary bones (Williams, 1988; 1990; Hundt et al., 2014). Cirripectes differs from closely related genera within the clade Williamsichthys by two major characters: a transverse row of uniform-length nuchal cirri connected by a membrane basally to form one to four groups, and a male genital structure consisting of a urogenital papilla with one or two long, tapering filaments associated with the gonopore (Williams, 1988).

Herein, we investigate the geographic origins of the endemic Hawaiian Scarface Blenny Cirripectes vanderbilti through an integrated molecular-phylogeographic-taxonomic approach. We collected specimens throughout Hawai $i$ and the tropical Pacific and through morphological and molecular analysis we reveal the existence of a previously undescribed species of Cirripectes with a limited distribution in the southern and central tropical Pacific. We describe the new species and conduct an extensive morphological examination of museum collections to ascertain its distribution. The restricted range and the phylogenetic position of the new species, combined with our molecular analyses of $C$. vanderbilti and other species in the genus, further 
96

97

98

99

100

101

102

103

104

105

106

107

108

109

110

111

112

113

114

115

116

117

118

119

120

121

122

123

124

125

126

127

128

129

130

131

132

133

134

135

resolve relationships within the genus Cirripectes and provide strong evidence for a southern route-to-colonization for the Hawaiian endemic.

\section{Materials \& Methods}

\section{Specimen collection}

We collected specimens of the endemic Hawaiian blenny Cirripectes vanderbilti throughout its range in the Hawaiian Islands as well as at Johnston Atoll. We collected specimens of $C$. variolosus - the nominal sister species to C. vanderbilti-as broadly as possible throughout the Central Pacific. Due to the opportunistic nature of our sampling and the difficulty of capturing these species in locations where ichthyocides are prohibited, our sampling efforts were limited to Kiritimati Island, Kiribati, the Marquesas Islands, the Society Islands, and scattered locations throughout French Polynesia and the South Pacific (Fig. 1). Samples were collected by the first author and collaborators at the Northwest Hawaiian Islands and Johnston Atoll under permit \#PMNM-2018-031 from the Papahānaumokuākea Marine National Monument and at Kiritimati under permit \#002/17 from the Republic of Kiribati Environment and Conservation Division. The second author and Serge Planes (CRIOBE) collected samples throughout French Polynesia under the permit "Permanent agreement, Délégation à la Recherche, French Polynesia". In addition to field collections, we expanded our geographical coverage through morphological examination of specimens of various Cirripectes species in the Smithsonian National Museum of Natural History in Washington, DC. Where fish were collected for this study, sampling protocols were approved by the University of Hawai' $i$ Institutional Animal Care and Use Committee under approval number 09-753-5. This study involved no experiments on living animals.

\section{Procedures with specimens}

We collected fishes by rotenone, pole spear, and hand-net. Specimens retained for museum collections were photographed and fixed in 10\% formalin before being transferred to $70 \%$ ethanol for long-term storage. Each specimen was sub-sampled for DNA analysis before formalin fixation by removing either the right pectoral fin (in the case of museum specimens) or a portion of the caudal fin and storing it in $>70 \%$ ethanol or salt-saturated DMSO solution (Seutin, White \& Boag, 1991).

\section{Morphological analysis}

Morphological data were taken in two categories: meristic characters and morphometrics. Detailed descriptions of counts and measures taken can be found in Williams (1988), whose methods we follow and build upon. Ranges for counts are provided when variable, with holotype value given in brackets. Morphometric measurements were taken to the nearest $0.1 \mathrm{~mm}$ using dial calipers. Lengths of specimens are presented in $\mathrm{mm}$ standard length (SL), measured from the tip of the snout to the center of the caudal peduncle at the posterior edge of the hypural plate. In 
136

137

138

139

140

141

142

143

144

145

146

147

148

149

150

151

152

153

154

155

156

157

158

159

160

161

162

163

164

165

166

167

168

169

170

171

172

173

174

175

addition to standard meristics, we used the following characters: depth at anus (DAN) (Fig. 2A), post-orbital to mid-nuchal distance (POMN), supraorbital cirri length (SOL), left/dorsal/right nuchal separation distance (NSD/L/R), lower nuchal to opercle distance (LNO), head length (HL) (Fig. 2B), male urogenital papilla type (Fig. 3), nuchal cirri type (Fig. 4A\&B), nuchal cirri counts (NUC), nasal cirri counts (NAC), supraorbital cirri counts (SOC), and number of lateralline tubes (LLT). We also classified the shape and structure of the sensory pore system that lies anterior and posterior to the lateral break (where present) in the transverse row of nuchal cirri (Fig. 4B-D). Data from morphological analyses were combined and analyzed using a principal component analysis (PCA) in R 3.6.1 (R Core Team, 2017). In order to reduce variation due to allometric differences, we scaled measurements proportional to SL or HL and to unit variance. The most informative principal components (PC1 and PC2) were visualized in a biplot using the $\mathrm{R}$ package ggbiplot ( $\mathrm{Vu}, 2011)$ and characters contributing most to principal component variation were identified using their loading values.

The following institutional codes are referenced to identify specimens in this study: Bernice Pauahi Bishop Museum (BPBM), National Museum of Natural History, Smithsonian Institution (USNM), California Academy of Sciences (CAS). A complete account of all specimens examined along with institutional catalog numbers is provided as supplemental information.

To better understand the geographical distribution of the new species described in this study and due to its high degree of morphological similarity to other species of Cirripectes, we examined BPBM and USNM fish collections to be sure that previously unidentified members of the new species were not erroneously included with other specimen lots.

\section{DNA extraction and sequencing}

Tissue samples were sent to USNM or Hawai'i Institute of Marine Biology (HIMB) for processing. DNA from specimens sent to USNM was extracted at the National Museum of Natural History Laboratories of Analytical Biology (LAB) with an AutoGenprep 965 (Autogen, Holliston, MA, USA) extraction robot after overnight digestion with proteinase-K in M2 buffer. Samples were amplified for cytochrome oxidase subunit I (COI) with the primers fishCOIF (TCAACYAATCAYAAAGATATYGGCAC ) and fishCOIR

(ACTTCYGGGTGRCCRAARAATCA) (Baldwin et al., 2009) using a PCR cocktail including 5 $\mu \mathrm{L}$ GoTaq Hot Start Mix (Promega), $0.1 \mu \mathrm{L} 20 \mu \mathrm{g} / \mu \mathrm{L}$ BSA, $0.3 \mu \mathrm{L}$ each $10 \mathrm{mM}$ primer and 0.5 $\mu \mathrm{L}$ dNTPs $\left(2.5 \mathrm{mM}\right.$ each) in a total volume of $10 \mu \mathrm{L}$. The thermocycler profile was: $95^{\circ} \mathrm{C} 7 \mathrm{~m}, 35$ cycles of $95^{\circ} \mathrm{C} 30 \mathrm{~s}, 50^{\circ} \mathrm{C} 30 \mathrm{~s}, 72^{\circ} \mathrm{C} 45 \mathrm{~s}$, ending with $72^{\circ} \mathrm{C} 2 \mathrm{~m}$. Samples processed at HIMB were extracted using either the EZNA-96 Tissue DNA Kit (Omega Bio-Tek, Norcross, GA, USA) following manufacturer's protocols or a modified version of the HotSHOT protocol of Meeker et al. (2007) and amplified for COI using the primers FishF1

(TCAACCAACCACAAAGACATTGGCAC) and FishR1

(TAGACTTCTGGGTGGCCAAAGAATCA) following the chemistry and thermocycler settings 
176 from Ward (2005). DNA sequencing was performed using fluorescently-labeled dideoxy 177 terminators on an ABI 3730XL Genetic Analyzer (Applied Biosystems, Foster City, CA, USA)

178 at the University of Hawai' 1 Advanced Studies of Genomics, Proteomics and Bioinformatics 179 sequencing facility and the LAB.

180

181

182

\section{Molecular and phylogenetic analyses}

183

184

185

186

187

188

189

190

191

192

193

194

195

196

197

198

199

200

201

202

203

204

205

206

207

208

209

210

211

212

213

214

215

We aligned resolved COI sequences in Geneious 10.2.6 (https://www.geneious.com) using the CLUSTAL-W algorithm. We examined relationships within putative species groups by constructing COI haplotype networks using the R script haplonet.r (https://dx.doi.org/10.5281/zenodo.3532180) and a modified version of the $\mathrm{R}$ package pegas (https://dx.doi.org/10.5281/zenodo.3647668). Pairwise genetic distances were calculated using the R script gdist.r (https://dx.doi.org/10.5281/zenodo.3532182) and genetic summary statistics were generated with pegas (Paradis, 2010). Population structure was investigated using analysis of molecular variance (AMOVA) in the R packages poppr (Kamvar, Tabima \& Grünwald, 2014) and pegas.

To assess phylogenetic relationships within Cirripectes, we aligned our sequences with unique COI sequences of other congeneric species from GenBank (Table 1), National Museum of Natural History Biorepository collections, and previous fish barcoding efforts in French Polynesia (Delrieu-Trottin et al., 2019). We used PartitionFinder 2 with greedy algorithm to select the best model(s) of nucleotide substitution partitioned by codon position, based on corrected Akaike Information Criterion (AICc) (Guindon et al., 2010; Lanfear et al., 2012; 2016). We rooted our reconstructions using Plagiotremus tapeinosoma, a confamilial outside of the Williamsichthys clade, as an outgroup. We conducted a Bayesian phylogenetic reconstruction using MrBayes 3.2.7 (Huelsenbeck \& Ronquist, 2001; Ronquist, 2004), running four independent searches for 200 million generations each, saving trees every 1,000 generations and discarding the first $20 \%$ as burn-in. We verified MCMC and model parameter convergence using Tracer v1.7.1 (Rambaut et al., 2018). Final trees were created with R (R Core Team, 2017) using the ggtree package (Yu et al., 2017). Phylogenetic computations were run on the University of Hawai' i Information Technology-Cyberinfrastructure High Performance Computing cluster.

\section{Nomenclatural acts}

The electronic version of this article in Portable Document Format (PDF) will represent a published work according to the International Commission on Zoological Nomenclature (ICZN), and hence the new names contained in the electronic version are effectively published under that Code from the electronic edition alone. This published work and the nomenclatural acts it contains have been registered in ZooBank, the online registration system for the ICZN. The ZooBank LSIDs (Life Science Identifiers) can be resolved and the associated information viewed through any standard web browser by appending the LSID to the prefix http://zoobank.org/. The

Peer) reviewing PDF | (2019:04:36574:1:1:CHECK 21 Feb 2020) 
216 LSID for this publication is: urn:Isid:zoobank.org:pub:E904BAB5-9C52-46A0-9B74-

217 530C39F571DE. The online version of this work is archived and available from the following

218 digital repositories: PeerJ, PubMed Central and CLOCKSS.

219

220

221

222

223

224

225

226

227

228

229

230

231

232

233

234

235

236

237

238

239

240

241

242

243

244

245

246

247

248

249

250

251

252

253

254

255

\section{Results}

\section{mtDNA sequences}

We resolved 641 base pairs of the mitochondrial cytochrome oxidase subunit I (COI) from 51 nominal individuals of Cirripectes variolosus from Kiritimati Island, Kiribati and Nuku Hiva, Marquesas, 82 individuals of $C$. vanderbilti from Hawai' $i$ and Johnston Atoll, and five uncertain individuals initially identified as C. variolosus from the Marquesas, Gambier, Austral Islands, and Palmyra Atoll. New sequences generated for this study have been deposited in GenBank and are available via accession numbers MN649877-MN650012.

The Hawaiian endemic Cirripectes vanderbilti has relatively high haplotype diversity driven by many singleton haplotypes $(h=0.93)$, but no apparent population structure in COI across its geographic range (AMOVA, $p>0.80, \Phi_{\mathrm{st}}=-0.01$ ). One haplotype is shared among almost all localities (from Kure Atoll to $\mathrm{O}^{`} \mathrm{ahu}$, including Johnston Atoll) (Fig. 5A). Due to limited sample sizes, we combined sequences from the adjacent islands Laysan, Lisianski, and French Frigate Shoals into a single population for the AMOVA analysis. The classic star-shaped pattern of the COI haplotype network for $C$. vanderbilti is indicative of a recent population expansion or high demographic turnover within Hawai' $i$ (Grant \& Bowen, 1998). Our collections of Cirripectes variolosus lacked sufficient sample sizes at most localities for population structure inference, but we detected strong differentiation between the Marquesas and Line Islands (AMOVA, $p<0.001$, $\Phi_{\text {st }}=0.96$ ). The COI haplotype networks for the specimens initially identified as $C$. variolosus (Fig. 5B) reveal two distinct lineages. One group (lineage A, C. variolosus) comprises the majority of individuals collected for genetic samples in the Marquesas and Society Islands, plus one from Kiritimati and the Marshall Islands. The second (lineage B, C. matatakaro) comprises all but one of the individuals collected from the Line Islands (Kiritimati and Palmyra) and the five "uncertain" individuals from the Marquesas, Gambier, and Austral Islands. The two haplotype lineages are separated by $\sim 46$ mutational steps and an uncorrected pairwise distance of $\sim 10.8 \%$. The Gambier Islands specimens appear to be genetically divergent within lineage B, as the haplotype network shows their COI haplotypes to be separated by a minimum of eight mutations (Fig. 5B). A BOLD search (Ratnasingham \& Hebert, 2007) indicates that lineage A matches $C$. variolosus to $100 \%$ identity, while lineage B produces no species-level database matches with greater than $92 \%$ identity.

\section{Phylogenetic inference}

The best-fit partitioning scheme for COI was GTR $+\Gamma, F 81+\Gamma$, and GTR $+\mathrm{I}+\Gamma$ (in order of codon position). Our COI tree (Fig. 6B) recovers two well-supported clades within the genus which correspond to nodes I and III of Williams' (1988) morphological phylogeny (Fig. 6A).

Peer) reviewing PDF | (2019:04:36574:1:1:CHECK 21 Feb 2020) 
256 Disagreements between our tree and the morphological tree may be due to cryptic lineages, lack 257 of phylogenetic-morphological concordance, incomplete taxon sampling, and/or limitation to a 258 single mitochondrial locus in our molecular analysis. The clade corresponding to node I contains 259 the Cirripectes quagga/alboapicalis/obscurus/jenningsi species group within which specific 260 relationships largely concur with the morphological phylogeny. The specimens identified as $C$. 261 alboapicalis are polyphyletic, with individuals from Rapa Nui (here labeled " $C$. patuki") forming 262 the sister group to C. alboapicalis and C. obscurus (de Buen, 1961; Delrieu-Trottin et al., 2018). 263 Cirripectes obscurus, considered a Hawaiian endemic, contains two individuals from Hawai' $\mathrm{i}$ in 264 addition to one from the Austral Islands (USNM 422996). Within C. quagga, Hawaiian 265 individuals occur on a separate branch, here labeled "C. lineopunctatus" after Strasburg (1956). 266 Upon examination of the type material for C. lineopunctatus (USNM 164198-164201), we were

267

268

269

270

271

272

273

274

275

276

277

278

279

280

281

282

283

284

285

286

287

288

289

290

291

292

293

294

295

unable to discern consistent differences from C. quagga. We did note the black-outlined white spots given in the description (Strasburg, 1956), although that coloration was not exclusive to the Hawaiian specimens.

The second major clade in our tree corresponds with node III of Williams (1988) (Fig. 6A). This group contains the new sequences (originally identified as $C$. variolosus) generated for this study and reveals that those individuals comprise two groups nested within two separate and divergent regions of the tree. Specimens from haplotype lineage A (C. variolosus; Fig. 5B) are shown to cluster with other individuals previously identified as $C$. variolosus in a well-supported $(>0.99$ posterior prob.) group basal to the other members of the clade. This position corresponds with its position in the morphological analysis. Specimens from haplotype lineage B (C. matatakaro; originally identified as $C$. variolosus) comprise a strongly supported ( $>0.99$ posterior prob.) group sister to the Hawaiian endemic $C$. vanderbilti. We recover C. filamentosus and $C$. chelomatus as sister taxa, both closely related to $C$. auritus, which is in agreement with the morphological tree. Our tree resolves the branching order for C. castaneus and C. stigmaticus, which occur in an unresolved trichotomy in the morphological tree. Cirripectes polyzona, part of the same trichotomy, is more distantly related in our analysis. However, it occurs at the only poorly supported ( $\sim 0.52$ posterior prob.) internal node in our tree, so its position is not certain. A group of individuals from Réunion Island in the Indian Ocean (identified in BOLD as $C$. castaneus) cluster as the sister to C. fuscoguttatus. Based on the specimen photographs and their collection locality, we believe it is most likely that these are actually $C$. randalli and have tentatively labeled them as such. We lack COI sequences from C. gilberti or C. hutchinsi, however, which may also co-occur in that locality. In addition, our incomplete taxon sampling may be the cause of the longer branches between C. randalli and C. fuscoguttatus.

Our COI data resolve some of the relationships among the Cirripectes (particularly the previously unresolved trichotomy with $C$. variolosus, $C$. vanderbilti and other species in the genus sharing the same basic nuchal cirri morphology), and reveal the lineage labeled Cirripectes matatakaro as the sister lineage to the Hawaiian endemic, from which it diverges by

Peer] reviewing PDF | (2019:04:36574:1:1:CHECK 21 Feb 2020) 
296

297

298

299

300

301

302

303

304

305

306

307

308

309

310

311

312

313

314

315

316

317

318

319

320

321

322

323

324

325

326

327

328

329

330

331

332

333

334

335

$\sim 4.2 \%$ (uncorrected pairwise distance). Based on our molecular and taxonomic analyses, we conclude that Cirripectes matatakaro constitutes a previously undescribed species.

\section{Cirripectes matatakaro sp. nov.}

\section{Suspiria Blenny}

urn:Isid:zoobank.org:act:B9D062E5-6D3D-4218-B225-BE31147B025B

\section{Holotype}

USNM 423364; adult male 60mm SL (Fig. 7A); Tupua'i, Austral Islands, French Polynesia, south end outer reef slope with dense coral $\left(23.4214^{\circ} \mathrm{S}, 149.44^{\circ} \mathrm{W}\right)$; depth $18-22 \mathrm{~m}$; field number AUST-242; collected by rotenone and hand net; collectors J. T. Williams, E. DelrieuTrottin, P. Sasal on 14 April 2013; vessel M/Y “Golden Shadow”.

\section{Paratypes}

USNM 409139 adult female 60mm SL field number MARQ-139 (Fig. 7B) and USNM 409140 male 41mm SL field number MARQ-140; Banc Clark, Marquesas Islands, French Polynesia $\left(8.08928^{\circ} \mathrm{S}, 139.635^{\circ} \mathrm{W}\right)$; depth $17-32 \mathrm{~m}$; collected by rotenone and hand net; collectors J.T. Williams, S. Planes, E. Delrieu-Trottin, P. Sasal, J. Mourier, M. Veuille, R. Galzin, T. Lison de Loma, and G. Mou-Tham on 28 October 2011; vessel R/V "Braveheart". USNM 404702 female 29mm SL field number GAM-791 and UNSM 404703 male 35mm SL field number GAM-792;

Tarauru-Roa, Gambier Islands, French Polynesia, east of Mangareva, outer reef slope off Tarauru-Roa Island, corals with rock and coral rubble in the channels $\left(23.1067^{\circ} \mathrm{S}, 134.854^{\circ} \mathrm{W}\right)$; depth 10-25m; collected by rotenone and hand net; collectors J.T. Williams, S. Planes, P. Sasal, and E. Delrieu-Trottin on 13 October 2010; vessel M/V “Claymore II". USNM 446765 female 43mm SL field number LV12/MHCV006; Palmyra Atoll, Line Islands $\left(5.891155^{\circ} \mathrm{N}\right.$, $162.084731^{\circ} \mathrm{W}$ ); collected by spear and hand net; collectors M. Gaither, M. Iacchei, D. Wagner, and D. Skillings on 18 April 2010. BPBM 16928 adult male 42mm \& 43mm SL (Fig. 8); Pitcairn Island; depth 27-30m; collected by rotenone; collectors J.E. Randall, D.B. Cannoy, and S.R. Christian on 23 December 1970. BPBM 16941 female 25mm \& 53mm SL; Pitcairn Island; depth 22-25m; collected by rotenone; collectors J.E. Randall, D.B. Cannoy, J.R. Haywood, J.D. Bryant, and S.R. Christian on 4 January 1971. BPBM 14060 adult female 52mm SL; Tabuaeran Island, Kiribati; collectors E.H. Chave and D.B. Eckert in July 1972. BPBM 12270 adult female $61 \mathrm{~mm}, 54 \mathrm{~mm}$, \& 55mm SL; Ducie Atoll, Pitcairn Islands; depth 30m; collected by rotenone; collectors J.E. Randall, R.R. Costello, D.B. Cannoy, S.R. Christian, and R.M. McNair on 15 January 1971. CAS 48965 adult female 64mm SL; Raroia Atoll, French Polynesia (16.0167 S, $\left.142.4333^{\circ} \mathrm{W}\right)$; collector J. Morrison for R.R. Harry on 8 July 1952.

\section{Diagnosis}

Cirripectes matatakaro can be distinguished from congeners by the following combination of characters: (1) male genital papilla with two widely separated slender filaments to either side of 
336

337

338

339

340

341

342

343

344

345

346

347

348

349

350

351

352

353

354

355

356

357

358

359

360

361

362

363

364

365

366

367

368

369

370

371

372

373

374 Color in alcohol

the gonopore, type I sensu Williams (1988) (Fig. 3A); (2) nuchal cirri divided into two, rarely three or four, groups always slightly separated dorsally on nape with bases swollen beneath ventralmost cirri on either side; (3) overall shape of the transverse row of nuchal cirri modally type I (Fig. 4A) and sometimes type II (Fig. 4B) (types C and G sensu Williams), with 32-38 independently based cirri; (4) dorsal separation in row of nuchal cirri $0.1-0.7 \mathrm{~mm}$ (median width $0.3 \mathrm{~mm}) ;(5)$ where interrupted laterally, lateral breaks in row of nuchal cirri $0-0.4 \mathrm{~mm}$ in width (median width $0 \mathrm{~mm}$ ); (6) sensory pore structure directly posterior to lateral center of row of nuchal cirri type I (Fig. 4C), posterior and parallel to row of nuchal cirri, does not visibly penetrate through break (where present); (7) 0-6 distinct LLT; (8) head coloration in life commonly bright reddish orange on upper section with bright red spots and/or slashes extending dorsally and posteriorly from the snout; (9) outer ring of iris bright orange-red in life.

\section{Description}

Dorsal-fin rays XII,14; anal-fin rays II, 15 (anal-fin spines of sexually mature males enveloped in fleshy rugosities, females with first of two anal-fin spines embedded in swollen tissue behind gonopore-first spine visible only in radiograph or osteological preparation); total procurrent caudal-fin rays 12; caudal-fin rays 13 (nine branched); pelvic-fin rays I, 4 (spine highly reduced and difficult to discern except in osteological preparation); pectoral-fin rays 15; vertebrae $10+20=30$ (precaudal+caudal); last pleural rib on vertebral centrum 11; posteriormost anal-fin ray split through base, borne on a single pterygiophore and counted as a single ray (Fig. 9); total nuchal cirri 32-38 [34]; supraorbital cirri 6-11 [9]; nasal cirri 7-12 [10]; LLT (when present on larger individuals; tubes increase in number with increasing SL) 1-6 [4]; last LLT (when present) at position vertically below dorsal-fin ray 5-13 [12]; lower lip smooth mesially; upper lip crenulae 23-50 [49]; gill rakers 21-29 [21]; pseudobranchial filaments on left side 7-10 [9]; maxillary teeth 202-239 [uncounted]; dentary teeth 83-96 [uncounted]; nuchal cirri consisting of 32-38 [34] independent cirri in two rows of nuchal cirri with membrane swollen ventrolaterally and rarely broken by a lateral gap halfway down; first dorsal-fin spine of adults approximately equal in length to second dorsal-fin spine (males and females); dorsal fin deeply incised above last dorsal-fin spine; dorsal-fin membrane attached to caudal peduncle anterior to caudal fin; cephalic pore system complex (six or more pores at most positions; number of pores increase with increasing SL); midsnout pores present; extra interorbital pore position with pores present; multiple pore positions behind row of nuchal cirri, pore/tube structure lies parallel to row of nuchal cirri and does not penetrate lateral break (where present) in row of cirri; male genital papilla with urogenital orifice located basally between two widely separated slender filaments $(<1.0 \mathrm{~mm}$ in length) on a fleshy swelling behind anus (type I sensu Williams, Fig. 3A); maximum observed SL about $65 \mathrm{~mm}$. Morphological data for selected characters of type specimens are provided in Table 2 . 
375 Subadults and adults with cream to brown colored head and body (head is lighter in color); 376 anterior half of the head with white slashes $(0.5-1.0 \mathrm{~mm}$ in width) extending dorsally and 377 posteriorly from the snout; dorsal fin translucent.

378

379 Color in life

380

381

382

383

384

385

386

387

388

389

390

391

392

393

394

395

396

397

398

399

400

401

402

403

404

405

406

407

408

409

410

411

412

413

414

Adults with dark brown (though rarely pale brown to white) body; although male and female life colors may sometimes be quite different, the color pattern is highly variable and we found no consistently observed male-female color differences; dark red to orange slashes on head extending dorsal and posterior from the snout and encircling the eye; nasal and supraorbital cirri bright reddish orange; dorsal half of head bright reddish orange; nuchal cirri dark purple/brown to black; pectoral-fin color pale brown to yellow-orange; spinous portion of dorsal fin with reddish spines; dorsal-fin membrane with a translucent triangular section below the first 8-10 spines, otherwise brown below with red streaks basally; rayed portion of dorsal fin with yellowish-brown rays; upper caudal-fin rays yellowish; lower rays dark brown; anal fin dark brown; iris color silver with yellow ring around pupil and bright reddish orange ring around outer portion of eye (Fig. 7, Fig 8, Fig. 10).

\section{Comparison}

Cirripectes matatakaro co-occurs with C. variolosus (its most morphologically similar congener) throughout its geographic range, but there is depth segregation in the Marquesas, Australs, Pitcairns, and Tuamotus, with C. variolosus typically found on reef crests at depths shallower than $5 \mathrm{~m}$ and C. matatakaro found on outer reef slopes between 10-32 $\mathrm{m}$ (usually greater than 20 $\mathrm{m})$. Morphologically, the two differ primarily in the structure of the sensory pore canals directly posterior to the central-lateral portion of the row of nuchal cirri. Cirripectes variolosus has type II (Fig. 4D) pore structures whereas C. matatakaro has type I (Fig. 4C). Cirripectes matatakaro can also be distinguished in life from C. variolosus by the color of the outer iris ring: in $C$. variolosus it is silver-grey whereas in C. matatakaro it is bright reddish orange. The new species differs from its closest phylogenetic relative, Cirripectes vanderbilti, in the shape of the male genital papilla (C. vanderbilti has type II, Fig. 3B), nuchal pore structure (C. vanderbilti has type III, Fig. 4E), and shape of the row of nuchal cirri itself (C. vanderbilti has type I, Fig. 4A). In the principal component analysis (PCA) of combined meristic and morphometric characters, PC1 and PC2 explained $27.1 \%$ and $13.6 \%$ of the total variance, respectively (Fig. 11). According to the PCA loadings, PC1 was most influenced by the ratio between the lengths of the first and last dorsal-fin spines, the HL:SL ratio, the number of nuchal cirri, the number of distinct bases on the row of nuchal cirri, and width of lateral breaks in the row of nuchal cirri $(0.30,0.25,0.24,-0.35$, -0.32 respectively). On the PC2 axis, the most influential factors were HL:SL ratio and the ratio of supraorbital cirri length to $\mathrm{HL}(0.24,-0.40)$. This fits the qualitative observations that $C$. matatakaro generally has greater HL relative to SL than C. vanderbilti or C. variolosus and more numerous nuchal cirri and narrower-to-absent separation at the lateral breaks in the row of nuchal cirri relative to $C$. variolosus (C. vanderbilti lacks these breaks entirely). The PCA biplot 
415 was clearly partitioned, indicating morphological divergence among species, particularly

416 showing the distinct morphospace occupied by C. matatakaro. The two C. matatakaro data

417 points outside the black normal ellipse represent the specimens from Tarauru-Roa in the

418 Gambier Islands, indicating morphological as well as genetic differentiation in this remote

419 locality.

420

421

\section{Distribution}

422 Cirripectes matatakaro is known from the Northern Line Islands (Kiritimati and Palmyra), the

423 Marquesas, and the Tuamotus and from Ducie Atoll and Pitcairn west to the Gambier and

424 Austral Islands (Fig. 1). Cirripectes variolosus and C. vanderbilti co-occur at Johnston Atoll and

425 to date, no specimens of $C$. matatakaro have been collected there. However, an examination of

426 the 13 C. variolosus specimens from that locality housed in the USNM fish collections (USNM

427 198731) revealed several individuals with characters resembling the new species. In addition,

428 several of those Johnston Island individuals grouped closely with $C$. matatakaro in the PCA

429 biplot (Fig. 11). Those specimens were collected in 1964 and the delicate nuchal pore structures

430 were degraded and very light in color, leaving them difficult to identify definitively. However,

431 we believe it is highly likely, especially given its status as sister to the Hawaiian endemic, that

432 the range of Cirripectes matatakaro includes Johnston Atoll. Williams (1988) quoted Gosline as

433 stating that no Hawaiian endemics occur sympatrically with their Pacific-wide counterparts at

434 Johnston Island. The emergence of Cirripectes matatakaro rather than C. variolosus as sister to

435 C. vanderbilti makes this once again an open question. In addition to the above, we conducted a

436 thorough morphological examination of the extensive holdings of the USNM C. variolosus

437 specimens from localities throughout the Pacific. Aside from the Johnston Atoll specimens

438 already mentioned, we found no additional individuals with the characteristics of the new

439 species. As such, we believe it is probable that the Central/Southeastern-Central Pacific

440 distribution we have so far observed is the entire geographical range of $C$. matatakaro.

441

442 Etymology

443 The specific epithet is i-Kiribati, consisting of the words "mata" (eye) and "takaro"

444 (ember/burning coal) and refers to the large, eager-seeming eyes and the reminiscence of the red

445 slashes on the face to smoldering embers or burning coals. The species was named in the i-

446 Kiribati language to honor the people and culture of Kiribati, where the first author first

447 encountered and collected the new species. The common name Suspiria Blenny is in reference to

448 the color palette of the 1977 Dario Argento film of the same name.

449

450 Remarks

451 Cirripectes matatakaro is noteworthy in habitat use for a member of this genus. In the southern 452 portion of its range, from Pitcairn to the Austral Islands, C. matatakaro has primarily been

453 collected from $>20 \mathrm{~m}$ depth, deeper than other known Cirripectes species. This may be a unique

454 habitat exploited by this species, although in the Line Islands (Kiritimati and Palmyra) we 
455

456

457

458

459

460

461

462

463

464

465

466

467

468

469

470

471

472

473

474

475

476

477

478

479

480

481

482

483

484

485

486

487

488

489

490

491

492

493

494

collected it from the shallow $(<5 \mathrm{~m})$ oceanic forereef habitat more typically inhabited by congeners. Williams (1988) remarked that certain "problematical" specimens of C. variolosus, which were collected from deeper reefs in the Pitcairn Islands exhibited a reddish-orange head, and he speculated that the coloration might be an artifact of their depth of occurrence. Upon reexamination of that material, we determined those specimens to be the new species. Thus, the reddish color is more likely to be a property of the species rather than a product of its habitat, as individuals from Kiritimati and Palmyra show similar color patterns. We have not seen consistent evidence of sexual dichromatism, however one individual photographed in situ at Kiritimati Island had a distinctively light grey body coloration that is sometimes seen in females of other species of Cirripectes (Fig. 10).

\section{Discussion}

Geographic origins have been investigated for many conspicuous, larger-bodied Hawaiian reef fishes, but few studies have focused on endemic cryptobenthic species. Cryptobenthic species are key and often-overlooked members of reef communities despite their diminutive size and relatively low standing biomass. They contribute disproportionately to coral reef food webs through steady larval supply and high mortality by predation (Brandl et al., 2018; 2019).

Combtooth blennies represent typical cryptobenthic fishes and pose an interesting phylogeographic question; they are highly sedentary as adults but may be quite dispersive as larvae; the closely related genus Ophioblennius showed low population structure and lacked genealogical concordance throughout the East Pacific (Muss et al., 2001). The species of the genus Cirripectes show considerable variation in range size, from small-range endemics such as C. heemstraorum, C. randalli, and C. vanderbilti, to species with very broad distributions such as C. quagga and C. stigmaticus (Williams, 1988; 2010). However, upon closer examination species with large geographic ranges have sometimes been shown to comprise multiple cryptic lineages, indicating that these fishes are less dispersive than was previously thought (Williams, 2010; Delrieu-Trottin et al., 2018). Cirripectes variolosus, which is known from across the Pacific Plate, has been associated in an unresolved phylogenetic trichotomy with the Hawaiian endemic $C$. vanderbilti (Williams, 1988). Our mtDNA phylogeny reveals that $C$. variolosus is among the species that mask cryptic diversity. Through an integrated taxonomic approach, we determined that a subset of specimens initially identified as $C$. variolosus constitute a new species, C. matatakaro. The new species is morphologically similar to $C$. variolosus, but our phylogenetic reconstruction shows $C$. matatakaro to be the sister species to $C$. vanderbilti. Our tree additionally provides support for C. patuki, a Rapa Nui endemic, and the possibility of an antitropical distribution for C. obscurus (Delrieu-Trottin et al., 2018). The data also suggest that Hawaiian $C$. quagga individuals may comprise a distinct lineage, warranting re-evaluation and possible resurrection of $C$. lineopunctatus (Strasburg, 1956). The COI tree, despite some differences in internal branching order, is largely in concordance with the original 1988 morphological phylogeny (Fig. 6A \& 6B). Greater taxon coverage and additional genetic markers may help resolve remaining differences as well as potentially reveal more cryptic 
495 lineages within widely distributed species. Our sampling coverage of the new species is limited

496 by sample size and geographic distribution, but its phylogenetic position, combined with

497 morphological analysis of museum specimens and consideration of their geographic

498 distributions, enables us to make inferences about the Pacific origin of C. vanderbilti.

499

500 Cirripectes matatakaro has been collected from the Line Islands, Marquesas, Tuamotus, Pitcairn

501 Islands, Gambier Islands, and Austral Islands. Cirripectes variolosus has been collected

502 extensively across the Pacific Plate, from Palau to the Marquesas and throughout Micronesia, the

503 South Pacific, and the Line Islands (Fig. 1). As the two species are morphologically very similar

504 to one another, we sought to determine whether museum lots of C. variolosus might contain

505 misidentified individuals of the new species. None of the specimens we examined from any

506 available locality matched characters of $C$. matatakaro, with the possible exception of the two

507 individuals from Johnston Atoll mentioned previously. After review of USNM and BPBM

508 museum collections, we believe it is highly likely that the current known range of C. matatakaro

509 reflects its true distribution, with Johnston Atoll remaining an uncertain but probable additional

510 locality. The limited distribution of the new species within the central South Pacific and its status

511 as sister to Cirripectes vanderbilti combine to strongly indicate a southern route-to-colonization

512 for the Hawaiian endemic. Johnston Atoll has been shown to be a stepping-stone for biodiversity

513 to enter the Hawaiian Islands (Leray et al., 2010; Gaither et al., 2011; Andrews et al., 2014;

514 Tenggardjaja, Bowen \& Bernardi, 2014), and thus constitutes a likely entry point to Hawai' $i$ for

515 the ancestor of $C$. vanderbilti. However, some studies have concluded that Hawaiian biodiversity

516 may arrive directly from the Line Islands, bypassing Johnston Atoll (Skillings, Bird \& Toonen,

517 2010; Concepcion et al., 2016). Additionally, Randall (1985) remarked upon the conspicuous

518 absence of a number of both wide-ranging and endemic Hawaiian fishes from Johnston Atoll.

519 The new species described in this study occurs throughout the Northern Line Islands (where it

520 makes up a majority of the specimens of Cirripectes sampled) but has yet to be collected from

521 Johnston. In the absence of specimens of $C$. matatakaro from Johnston Atoll and given the

522 limited genetic coverage we currently possess, both routes are possible, though both support the

523 southern route hypothesis.

524

\section{Conclusions}

526 The Hawaiian Archipelago is one of the most isolated island groups in the world and the origin

527 of its marine species is an important question. Hawaiian biodiversity is thought to arrive either

528 from the Western Pacific, via the Kuroshio Current, or from the south, via dispersal from

529 Johnston Atoll or the Line Islands. The Scarface Blenny Cirripectes vanderbilti, which is

530 endemic to the Hawaiian Islands and Johnston Atoll, was long thought to be closely related to

531 the widespread C. variolosus. Through genetic and taxonomic analyses, we showed that the

532 sister species to $C$. vanderbilti is a new species, $C$. matatakaro, that is known from the Line

533 Islands south to the Marquesas, Pitcairn, Tuamotus, Gambier, and Austral Islands. Its limited

534 distribution throughout islands to the south of Hawai' $i$ and its status as sister to the Hawaiian 
535 endemic strongly indicates a southern route-to-colonization, although the lack of specimens from

536

537

538

539

540

541

542

543

544

545

546

547

548

549

550

551

552

553

554

555

556

557

558

559

560

561

562

563

564

565

566

567

568

569

570

571

572

573

574

Johnston Atoll leaves the specific pathway an open question.

Our work, and other recent studies, shows that the genus Cirripectes contains more cryptic diversity than previously thought. These results highlight the importance of ongoing genetic and biodiversity inventories on coral reefs, particularly as these habitats are increasingly under threat. Investigation of often-overlooked groups such as cryptobenthic reef fishes may uncover interesting evolutionary patterns, as in the case of Cirripectes, where widespread taxa are found to comprise multiple cryptic lineages with adjunct geographic ranges, suggesting parapatry as well as allopatry as evolutionary mechanisms in fishes. Our work also showcases the value of natural history collections to taxonomic and biogeographic research. Despite low sample numbers and narrow geographic coverage for our phylogeographic/genetic analyses, we were able to use museum specimens to make inferences about species range sizes and historic routes to colonization. Combtooth blennies and other cryptobenthic fishes often utilize vulnerable, high-energy surge zone habitats and may be underrepresented in museum collections as these habitats are difficult and/or dangerous to sample. As mass coral bleaching events and habitat degradation increase worldwide, we risk extensive biodiversity loss before we are even aware of its existence.

\section{Acknowledgements}

For field assistance we thank S.Planes, E. Delrieu-Trottin, P. Sasal, J. Mourier, M. Veuille, R. Galzin, T. Lison de Loma, G. Mou-Tham, M. Gaither, M. Iacchei, D. Wagner, D. Skillings, B. Bowen, R. Kosaki, S. Karl, R. Coleman, C. Westbrook, D. Kraft, and J. Copus. For logistic support we thank David Pence and Jason Jones from the University of Hawai'i Dive Safety Office. For field and logistical support on Kiritimati Island, we thank Patrick Price, Taburuea Tomataake, Karakaua Marakia, and the Frigate Bird Resting Cross Villages at Tabwakea. We thank John E. Randall for taking the photograph used in Figure 8 and for the donation of his photographic slides to the National Museum of Natural History. We thank David Rolla for the in-situ photograph in Figure 10. For i-Kiribati language assistance, we thank Takuia Uakeia from University of the South Pacific, Tarawa and Taratau Kirata from Kiribati Fisheries Division, Kiritimati. We thank Janina Larenas for reminding us of Dario Argento and his use of color, and for suggesting the common name. We gratefully acknowledge the technical support and advanced computing resources from the University of Hawai'i Information Technology Services - Cyberinfrastructure. We are grateful to T. Frogier, P. Mery and the Centre Plongée Marquises (Xavier (Pipapo) and Marie Curvat), for their field assistance in the Gambier, the Marquesas, and the Australs along with the crew of the Claymore II, Braveheart and the Golden Shadow. We thank the Ministère de l'Environnement de Polynésie, the Délégation à la Recherche Polynésie, the Mairie of Nuku-Hiva, and the people of the Marquesas Islands for their kind and generous support of the project as we traveled throughout the islands. We thank Jerry Finan, Erika Wilbur, Shirleen Smith, Kris Murphy, Diane Pitassy and Sandra Raredon of the Division of Fishes

Peer) reviewing PDF | (2019:04:36574:1:1:CHECK 21 Feb 2020) 
575 (National Museum of Natural History) for assistance in preparations for the French Polynesia 576 trips and processing specimens, and Lee Weigt, Amy Driskell, Jeffrey Hunt and Kenneth

577 Macdonald III and Meaghan Parker Forney of the Laboratories of Analytical Biology

578 (Smithsonian Institution) for assistance in molecular analysis of samples. We thank the staff of

579 the CRIOBE and particularly Yannick Chancerelle for logistical support in French Polynesia.

580 We thank Brian Bowen for helpful comments and discussion regarding an initial draft of this

581 paper. Finally, we thank Luiz Rocha and two anonymous reviewers for constructive comments

582 and suggestions on an earlier version of this paper. Any findings, and conclusions or

583 recommendations expressed in this material are those of the author(s) and do not necessarily

584 reflect the views of the National Science Foundation. The views expressed herein are those of the

585 author(s) and do not necessarily reflect the views of NOAA or any of its subagencies. This is

586 contribution \#JC-18-18 from the Hawai'i Sea Grant College Program, \#1776 from the Hawai' $i$

587 Institute of Marine Biology, and \#XXXX from the School of Ocean and Earth Science and

588 Technology at University of Hawai'i.

589

590 References

591 Andrews KR, Moriwake VN, Wilcox C, Grau EG, Kelley C, Pyle RL, Bowen BW 2014.

592

593

594

595

596

597

598

599

600

601

602

603

604

605

606

607

608

609

610

611

612

613

614

615

616

617

618 Phylogeographic Analyses of Submesophotic Snappers Etelis coruscans and Etelis "marshi" (Family Lutjanidae) Reveal Concordant Genetic Structure across the Hawaiian Archipelago. PLOS ONE 9:e91665. DOI: 10.1371/journal.pone.0091665.

Baldwin CC, Mounts JH, Smith DG, Weigt LA 2009. Genetic identification and color descriptions of early life-history stages of Belizean Phaeoptyx and Astrapogon (Teleostei: Apogonidae) with Comments on identification of adult Phaeoptyx. Zootaxa.

Bird CE, Holland BS, Bowen BW, Toonen RJ 2011. Diversification of sympatric broadcast-spawning limpets (Cellana spp.) within the Hawaiian archipelago. Molecular Ecology 20:2128-2141. DOI: 10.1111/j.1365-294X.2011.05081.x.

Brandl SJ, Goatley CHR, Bellwood DR, Tornabene L 2018. The hidden half: ecology and evolution of cryptobenthic fishes on coral reefs. Biological Reviews 206:227. DOI: $10.1111 /$ brv. 12423 .

Brandl SJ, Tornabene L, Goatley CHR, Casey JM, Morais RA, Côté IM, Baldwin CC, Parravicini V, Schiettekatte NMD, Bellwood DR 2019. Demographic dynamics of the smallest marine vertebrates fuel coral-reef ecosystem functioning. 53:eaav3384. DOI: 10.1126/science.aav3384.

Briggs JC, Bowen BW 2012. A realignment of marine biogeographic provinces with particular reference to fish distributions. Journal of Biogeography 39:12-30. DOI: 10.1111/j.13652699.2011.02613.x.

Concepcion GT, Kenyon J, Baums IB, Toonen RJ 2016. Genetic evidence for possible coral larval dispersal from the Northern Line Islands to the Hawaiian Archipelago. Galaxea, Journal of Coral Reef Studies 18:9-11.

Craig MT, Eble JA, Bowen BW 2010. Origins, ages and population histories: comparative phylogeography of endemic Hawaiian butterflyfishes (genus Chaetodon). Journal of Biogeography 37:2125-2136. DOI: 10.1111/j.1365-2699.2010.02358.x.

de Buen F 1961. Los peces de la Isla de Pascua. Boletin de la Sociedad de Biologia de Concepción 35/36:3-80. 
619 Delrieu-Trottin E, Trnski T, Rapu-Edmunds C, Neglia V, Rapu-Edmunds C, Planes S, Trnski T,

620

621

622

623

624

625

626

627

628

629

630

631

632

633

634

635

636

637

638

639

640

641

642

643

644

645

646

647

648

649

650

651

652

653

654

655

656

657

658

659

660

661

662

663

664 Rapu-Edmunds C, Saenz-Agudelo P, Liggins L, Trnski T, Williams JT, Rapu-Edmunds C 2018. Evidence of cryptic species in the blenniid Cirripectes alboapicalis species complex, with zoogeographic implications for the South Pacific. ZooKeys 810:127-138. DOI: 10.3897/zookeys.810.28887.

Delrieu-Trottin E, Williams JT, Pitassy D, Driskell A, Hubert N, Viviani J, Cribb TH, Espiau B, Galzin R, Kulbicki M, de Loma TL, Meyer C, Mourier J, Mou-Tham G, Parravicini V, Plantard P, Sasal P, Siu G, Tolou N, Veuille M, Weigt L, Planes S 2019. A DNA barcode reference library of French Polynesian shore fishes. Scientific Data 6:1-8. DOI: 10.1038/s41597-019-0123-5.

DeMartini EE, Friedlander AM 2004. Spatial patterns of endemism in shallow-water reef fish populations of the Northwestern Hawaiian Islands. Marine Ecology Progress Series 271:281-296. DOI: 10.3354/meps271281.

DiBattista JD, Wilcox C, Craig MT, Rocha LA, Bowen BW 2010. Phylogeography of the Pacific Blueline Surgeonfish, Acanthurus nigroris, Reveals High Genetic Connectivity and a Cryptic Endemic Species in the Hawaiian Archipelago. Journal of Marine Biology 2011:1-17. DOI: $10.1155 / 2011 / 839134$.

Gaither MR, Bernal MA, Coleman RR, Bowen BW, Jones SA, Simison WB, Rocha LA 2015. Genomic signatures of geographic isolation and natural selection in coral reef fishes. Molecular Ecology 24:1543-1557. DOI: 10.1111/mec.13129.

Gaither MR, Jones SA, Kelley C, Newman SJ, Sorenson L, Bowen BW 2011. High Connectivity in the Deepwater Snapper Pristipomoides filamentosus (Lutjanidae) across the Indo-Pacific with Isolation of the Hawaiian Archipelago. PLOS ONE 6:e28913. DOI: 10.1371/journal.pone.0028913.

GBIF.org 2019. GBIF Occurrence Download. DOI: https://doi.org/10.15468/dl.ndswit.

Gosline WA 1955. The Inshore Fish Fauna of Johnston Island, a Central Pacific Atoll. Pacific Science 9.

Grant W, Bowen BW 1998. Shallow population histories in deep evolutionary lineages of marine fishes: insights from sardines and anchovies and lessons for conservation. Journal of Heredity 89:415-426. DOI: 10.1093/jhered/89.5.415.

Guindon S, Dufayard J-F, Lefort V, Anisimova M, Hordijk W, Gascuel O 2010. New Algorithms and Methods to Estimate Maximum-Likelihood Phylogenies: Assessing the Performance of PhyML 3.0. Systematic biology 59:307-321. DOI: 10.1093/sysbio/syq010.

Hodge JR, Herwerden L, Bellwood DR 2014. Temporal evolution of coral reef fishes: global patterns and disparity in isolated locations. Journal of Biogeography 41:2115-2127. DOI: $10.1111 /$ jbi.12356.

Hourigan TF, Reese ES 1987. Mid-ocean isolation and the evolution of Hawaiian reef fishes. Trends in Ecology \& Evolution 2:187-191. DOI: 10.1016/0169-5347(87)90018-8.

Huelsenbeck JP, Ronquist F 2001. MRBAYES: Bayesian inference of phylogenetic trees. Bioinformatics (Oxford, England) 17:754-755. DOI: 10.1093/bioinformatics/17.8.754. Hundt PJ, Iglésias SP, Hoey AS, Simons AM 2014. A multilocus molecular phylogeny of combtooth blennies (Percomorpha: Blennioidei: Blenniidae): Multiple invasions of intertidal habitats. 70:47-56. DOI: 10.1016/j.ympev.2013.09.001.

Kamvar ZN, Tabima JF, Grünwald NJ 2014. Poppr: an R package for genetic analysis of populations with clonal, partially clonal, and/or sexual reproduction. PeerJ 2:e281. DOI: 10.7717/peerj.281.

Peer) reviewing PDF | (2019:04:36574:1:1:CHECK 21 Feb 2020) 
665 Kane C, Kosaki RK, Wagner D 2014. High levels of mesophotic reef fish endemism in the

666

667

668

669

670

671

672

673

674

675

676

677

678

679

680

681

682

683

684

685

686

687

688

689

690

691

692

693

694

695

696

697

698

699

700

701

702

703

704

705

706

707

708

709

710
Northwestern Hawaiian Islands. Bulletin of Marine Science 90:693-703. DOI:

10.5343/bms.2013.1053.

Kosaki RK, Pyle RL, Leonard JC, Hauk BB, Whitton RK, Wagner D 2016. 100\% endemism in mesophotic reef fish assemblages at Kure Atoll, Hawaiian Islands. Marine Biodiversity 90:1-2. DOI: 10.1007/s12526-016-0510-5.

Lanfear R, Calcott B, Ho SYW, Guindon S 2012. PartitionFinder: Combined Selection of Partitioning Schemes and Substitution Models for Phylogenetic Analyses. Molecular biology and evolution 29:1695-1701. DOI: 10.1093/molbev/mss020.

Lanfear R, Frandsen PB, Wright AM, Senfeld T, Calcott B 2016. PartitionFinder 2: New Methods for Selecting Partitioned Models of Evolution for Molecular and Morphological Phylogenetic Analyses. Molecular biology and evolution 34:772-773. DOI:

10.1093/molbev/msw260.

Leray M, Beldade R, Holbrook SJ, Schmitt RJ, Planes S, Bernardi G 2010. Allopatric Divergence and Speciation in Coral Reef Fish: the Three-spot Dascyllus, Dascyllus Trimaculatus, Species Complex. Evolution 64:1218-1230. DOI: 10.1111/j.15585646.2009.00917.x.

Meeker ND, Hutchinson SA, Ho L, Trede NS 2007. Method for isolation of PCR-ready genomic DNA from zebrafish tissues. BioTechniques 43:610-614. DOI: 10.2144/000112619.

Muss A, Ross Robertson D, Stepien CA, Wirtz P, Bowen BW 2001. Phylogeography of Ophioblennius: the Role of Ocean Currents and Geography in Reef Fish Evolution. Evolution 55:561-572. DOI: 10.1554/0014-3820(2001)055[0561:POOTRO]2.0.CO;2.

Paradis E 2010. pegas: an R package for population genetics with an integrated-modular approach. Bioinformatics (Oxford, England) 26:419-420. DOI: 10.1093/bioinformatics/btp696.

R Core Team 2017. R: A Language and Environment for Statistical Computing. R Foundation for Statistical Computing, Vienna, Austria. http://www.R-project.org/.

Rambaut A, Drummond AJ, Xie D, Baele G, Suchard MA 2018. Posterior Summarization in Bayesian Phylogenetics Using Tracer 1.7. Systematic biology 67:901-904. DOI: 10.1093/sysbio/syy032.

Randall JE 1998. Zoogeography of shore fishes of the Indo-Pacific region. Zoological Studies $37: 227-268$.

Randall JE 2007. Reef and shore fishes of the Hawaiian Islands. University of Hawai'i Press. Randall JE, Lobel PS, Chave EH 1985. Annotated checklist of the fishes of Johnston Island. Pacific Science 25:407-417.

Ratnasingham S, Hebert PDN 2007. bold: The Barcode of Life Data System (http://www.barcodinglife.org). Molecular Ecology Notes 7:355-364.

Ronquist F 2004. Bayesian inference of character evolution. Trends in Ecology \& Evolution 19:475-481. DOI: 10.1016/j.tree.2004.07.002.

Seutin G, White BN, Boag PT 1991. Preservation of avian blood and tissue samples for DNA analyses. Canadian Journal of Zoology 69:82-90. DOI: 10.1139/z91-013.

Skillings DJ, Bird CE, Toonen RJ 2010. Gateways to Hawai'i: Genetic Population Structure of the Tropical Sea Cucumber Holothuria atra. Journal of Marine Biology 2011:1-16. DOI: $10.1155 / 2011 / 783030$.

Smithsonian Institution National Museum of Natural History Fish Illustration Collection 1970, Catalog \#FIN 26922. http://n2t.net/ark:/65665/343b6d2a2-93ac-4c5f-80ef-ce58b3a99dc8

Peer] reviewing PDF | (2019:04:36574:1:1:CHECK 21 Feb 2020) 
711 Strasburg DW 1956. Notes on the blennioid fishes of Hawaii with descriptions of two new $712 \quad$ species. Pacific Science 10:241-267.

713 Tenggardjaja KA, Bowen BW, Bernardi G 2014. Vertical and Horizontal Genetic Connectivity

714 in Chromis verater, an Endemic Damselfish Found on Shallow and Mesophotic Reefs in the

715 Hawaiian Archipelago and Adjacent Johnston Atoll. PLOS ONE 9:e115493. DOI:

$716 \quad$ 10.1371/journal.pone.0115493.

717 Vu VQ 2011. ggbiplot: A ggplot2 based biplot. $R$ package version 0.55.

718 Ward RD, Zemlak TS, Innes BH, Last PR, Hebert PDN 2005. DNA barcoding Australia's fish

719 species. Philosophical Transactions of the Royal Society B: Biological Sciences 360:1847-

720 1857. DOI: $10.1098 /$ rstb.2005.1716.

721 Williams JT. 1986. Phylogenetic relationships and taxonomic revision of the Blenniid Fish

722 genera Cirripectes and Scartichthys. PhD Thesis. University of Florida.

723

724

725

726

727

728

729

730

731

Williams JT 1988. Revision and phylogenetic relationships of the blenniid fish genus Cirripectes. Indo-Pacific Fishes.

Williams JT 1990. Phylogenetic relationships and revision of the blenniid fish genus Scartichthys. Smithsonian Contributions to Zoology.

Williams JT 2010. A new species of blenny, Cirripectes heemstraorum, from Cape Vidal, South Africa (family Blenniidae). Smithiana Bulletin.

Yu G, Smith DK, Zhu H, Guan Y, Lam TTY 2017. ggtree: an r package for visualization and annotation of phylogenetic trees with their covariates and other associated data. Methods in Ecology and Evolution 8:28-36. DOI: 10.1111/2041-210X.12628. 


\section{Figure 1}

Known geographic distributions of Cirripectes variolosus, C. vanderbilti, and C. matatakaro sp. nov.

Green circles: Cirripectes variolosus. Magenta triangles: $C$. vanderbilti. Orange squares: $C$. matatakaro sp. nov. Black inverted triangle marks the location of Johnston Atoll. Occurrence data for C. variolosus and C. vanderbilti (constrained to USNM, BPBM, and CAS collections) downloaded from Global Biodiversity Information Facility (GBIF.org, 2019).

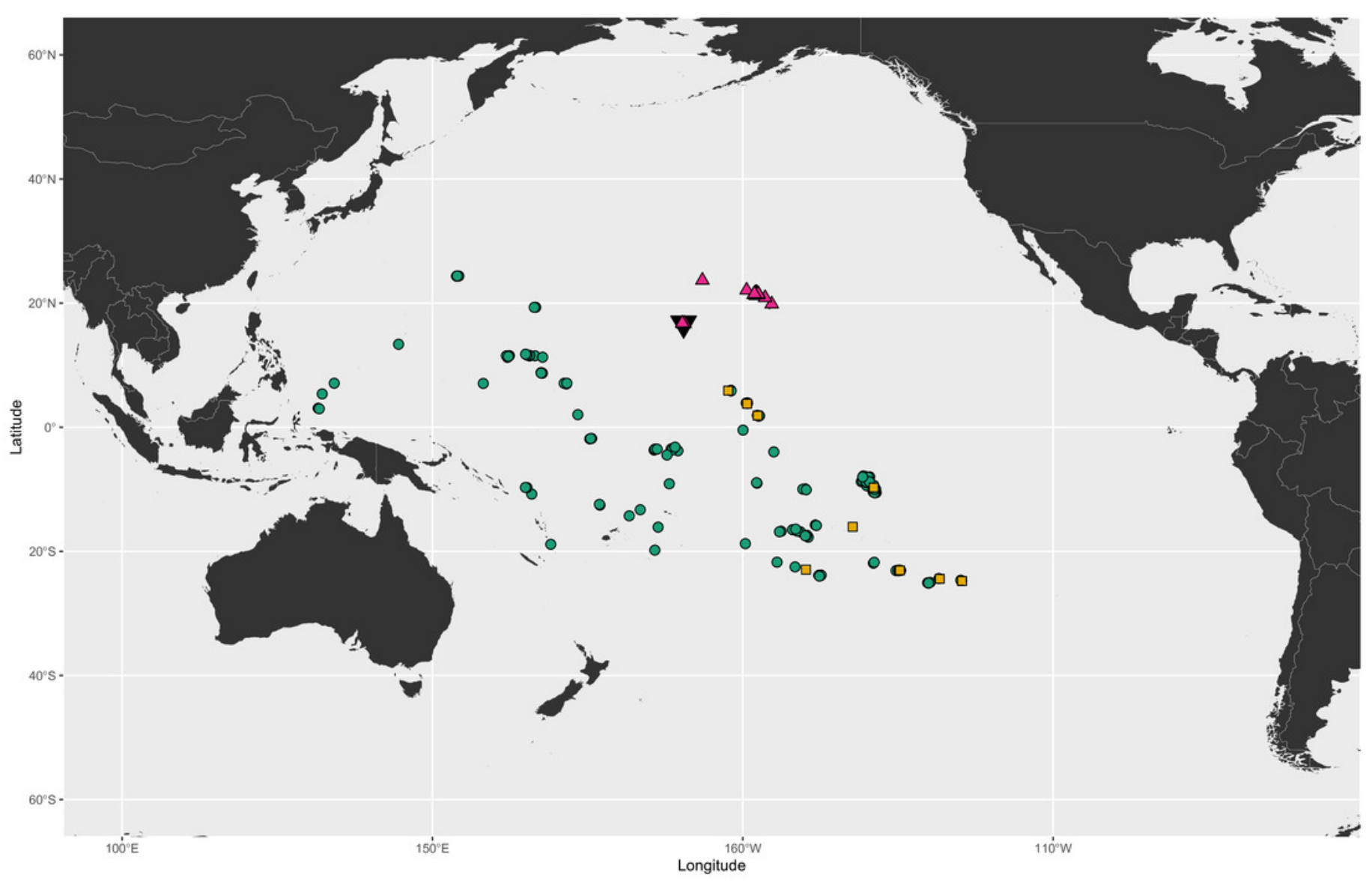


Figure 2 (on next page)

Schematic drawings showing morphological measurements for Combtooth Blennies (genus Cirripectes) following the methods of Williams (1988) .

(A) Body measurements (specimen: 29mm SL female paratype, USNM 404702, Gambier Islands). (B) Measurements of the head. For abbreviations and characters not displayed in this drawing, see Methods. Photograph in (A) by Jeffrey T. Williams, Smithsonian Institution. Drawing in (B) adapted from Williams (1986) and used with the author's permission. 
A
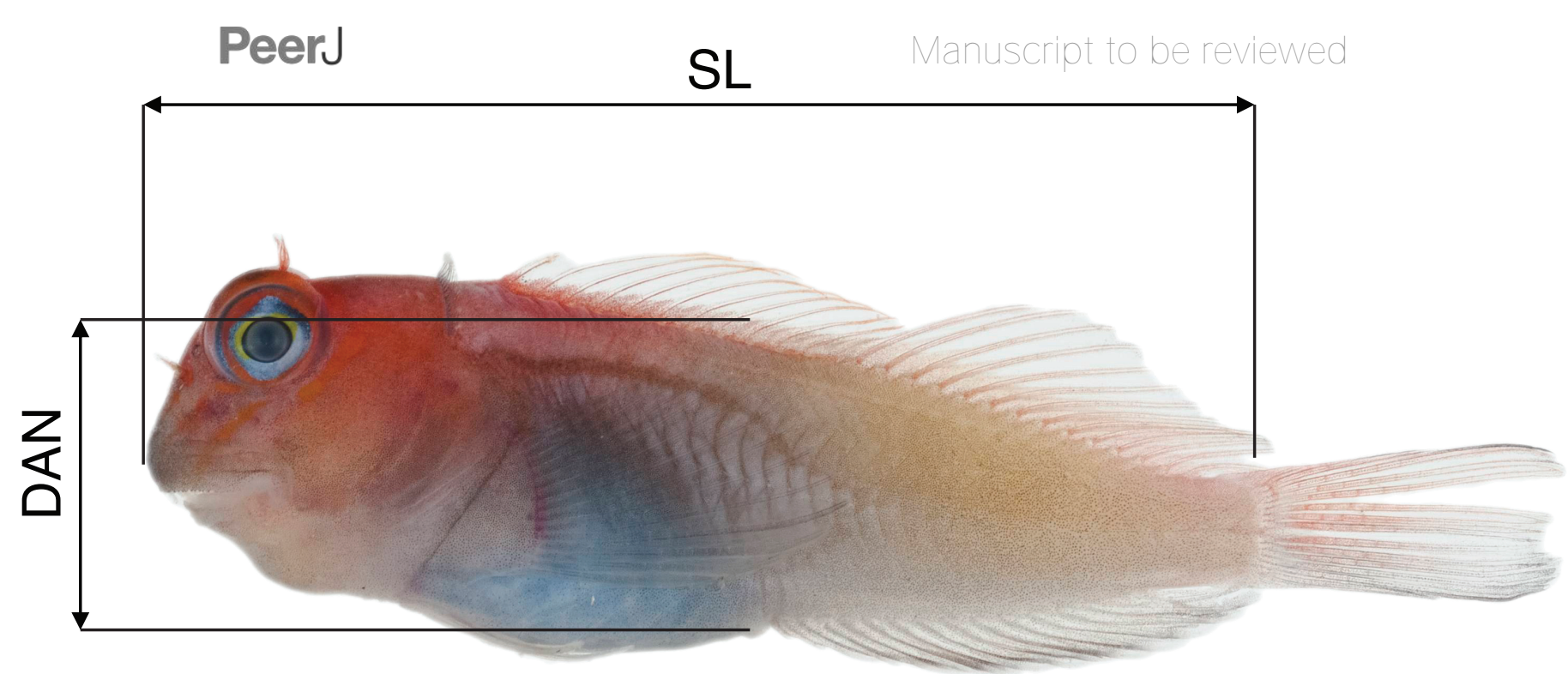

B

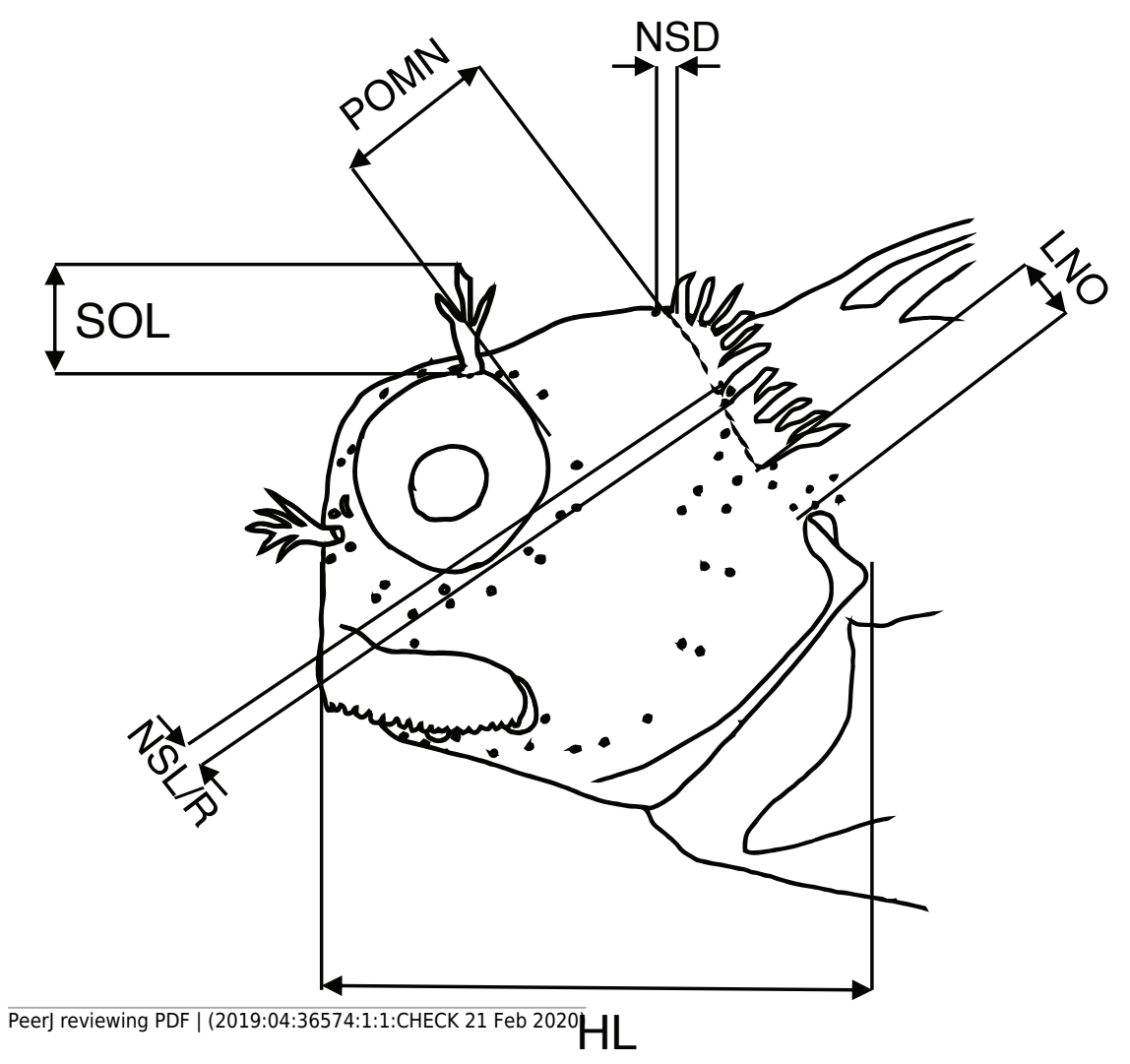



Figure 3

Ventral views of male urogenital papillae (anterior is up).

(A) Type I, characteristic of Cirripectes variolosus and C. matatakaro sp. nov. (B) Type II, characteristic of C. vanderbilti. Adapted from Williams (1986), with the author's permission.

A

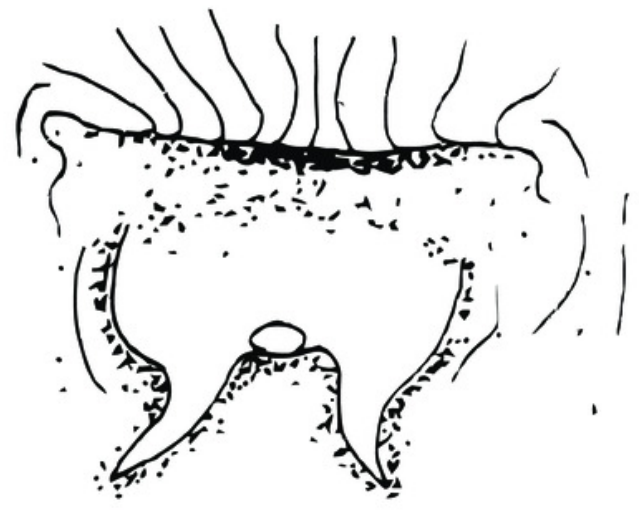

B

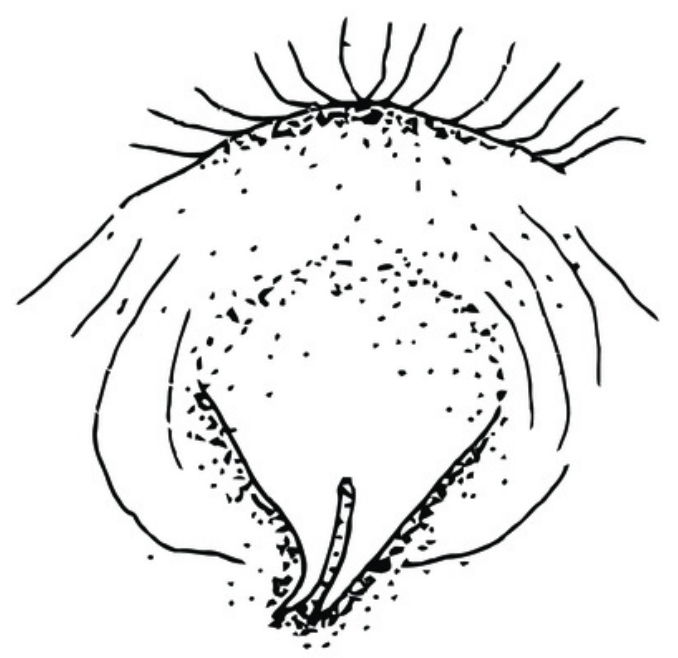


Figure 4

Characteristics of nuchal cirri and associated sensory pore canals.

(A) Type I nuchal cirri row: Cirripectes vanderbilti \& C. matatakaro. (B) Type II nuchal cirri row: $C$. variolosus. (C-E) Structure of pore system posterior to lateral center of nuchal cirri row. (C) type I: C. matatakaro; (D) type II: C. variolosus; (E) type III: C. vanderbilti.

A

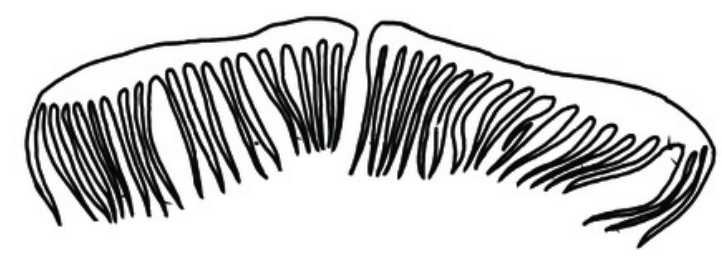

C

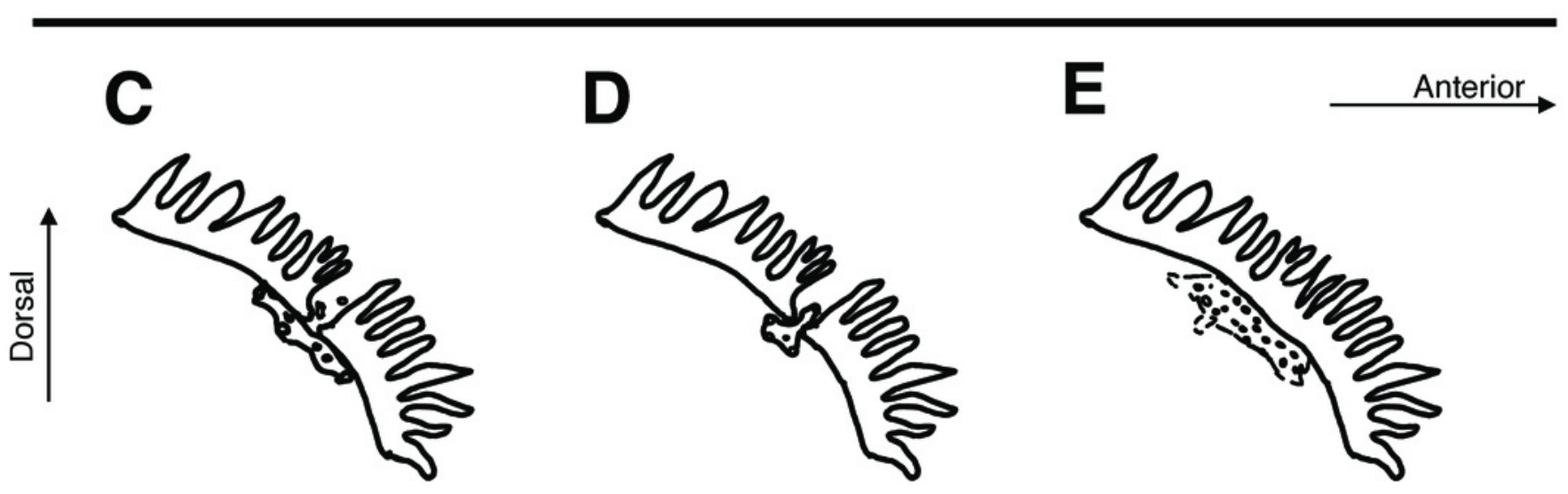

B

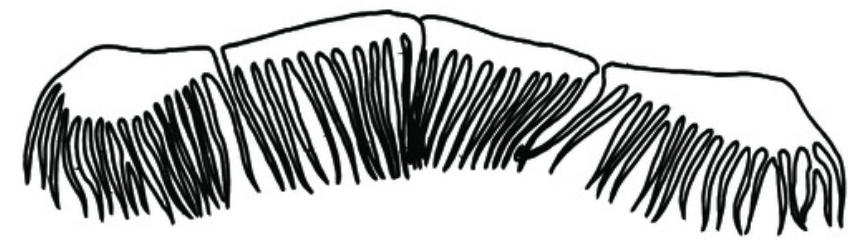




\section{Figure 5}

COI haplotype networks.

Each circle represents a unique haplotype. Lines connecting circles indicate a single mutation step, with hash marks indicating additional mutations. Haplotypes are color-coded by location and circle size is proportional to haplotype frequency. Smallest circles represent haplotypes detected once. (A) Cirripectes vanderbilti. (B) C. "variolosus" (incl. C. matatakaro sp. nov.)

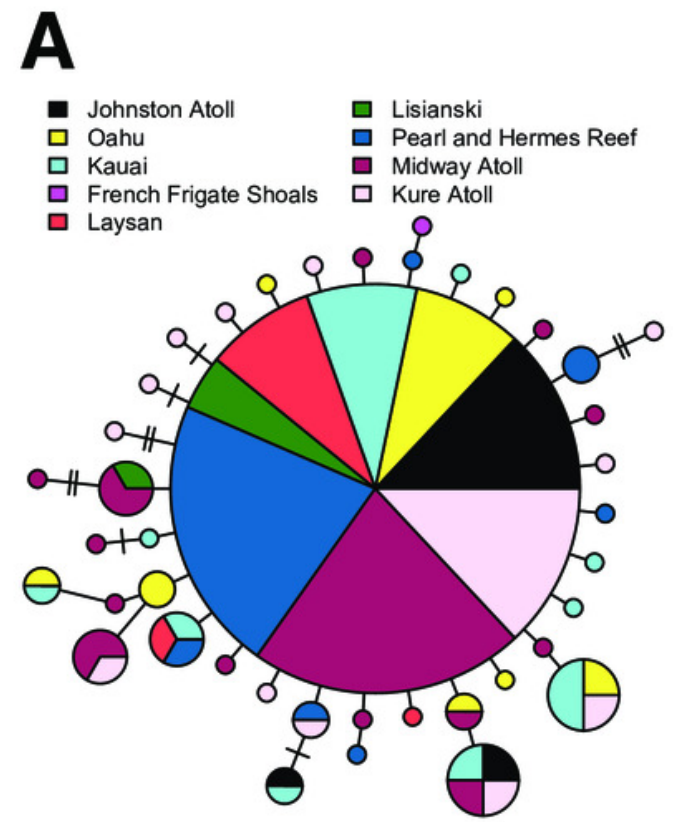

B

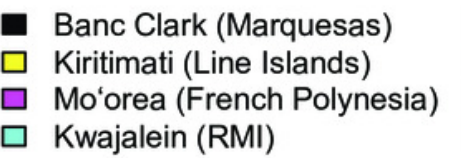
Nuku Hiva (Marquesas)

$\square$ Palmyra Atoll (Line Islands)

$\square$ Tarauru-Roa (Gambier)

$\square$ Tubuai (Australs)

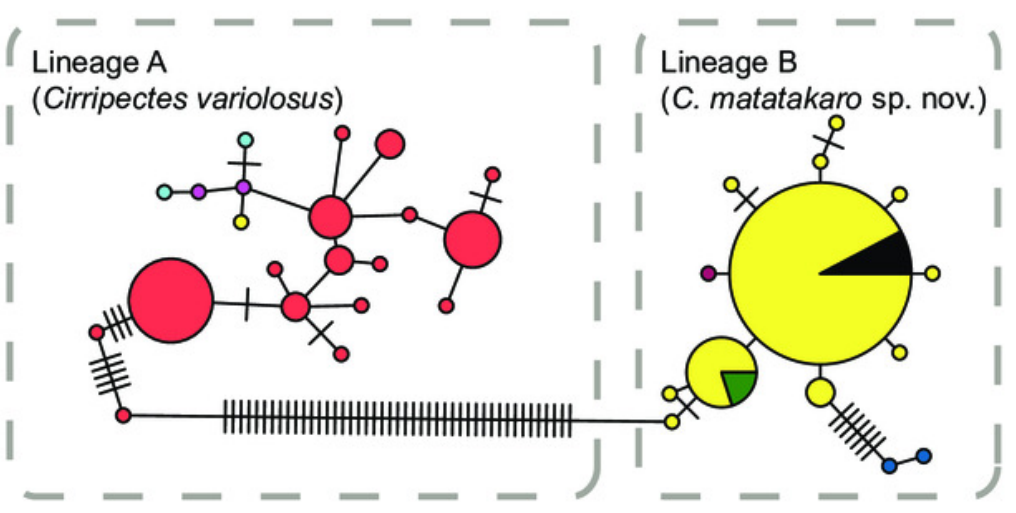


Figure 6

Phylogenetic hypotheses for Combtooth Blenny genus Cirripectes

(A) Phylogeny based on morphological analysis, sensu Williams (1988). (B) Rooted Bayesian phylogenetic reconstruction based on cytochrome oxidase subunit I (COI). Sister species C. vanderbilti and C. matatakaro sp. nov. are at right center. Node symbols are color coded by posterior probability: white: $<60 \%$, light grey: $60-75 \%$, dark grey: $75-95 \%$, black: $>95 \%$.

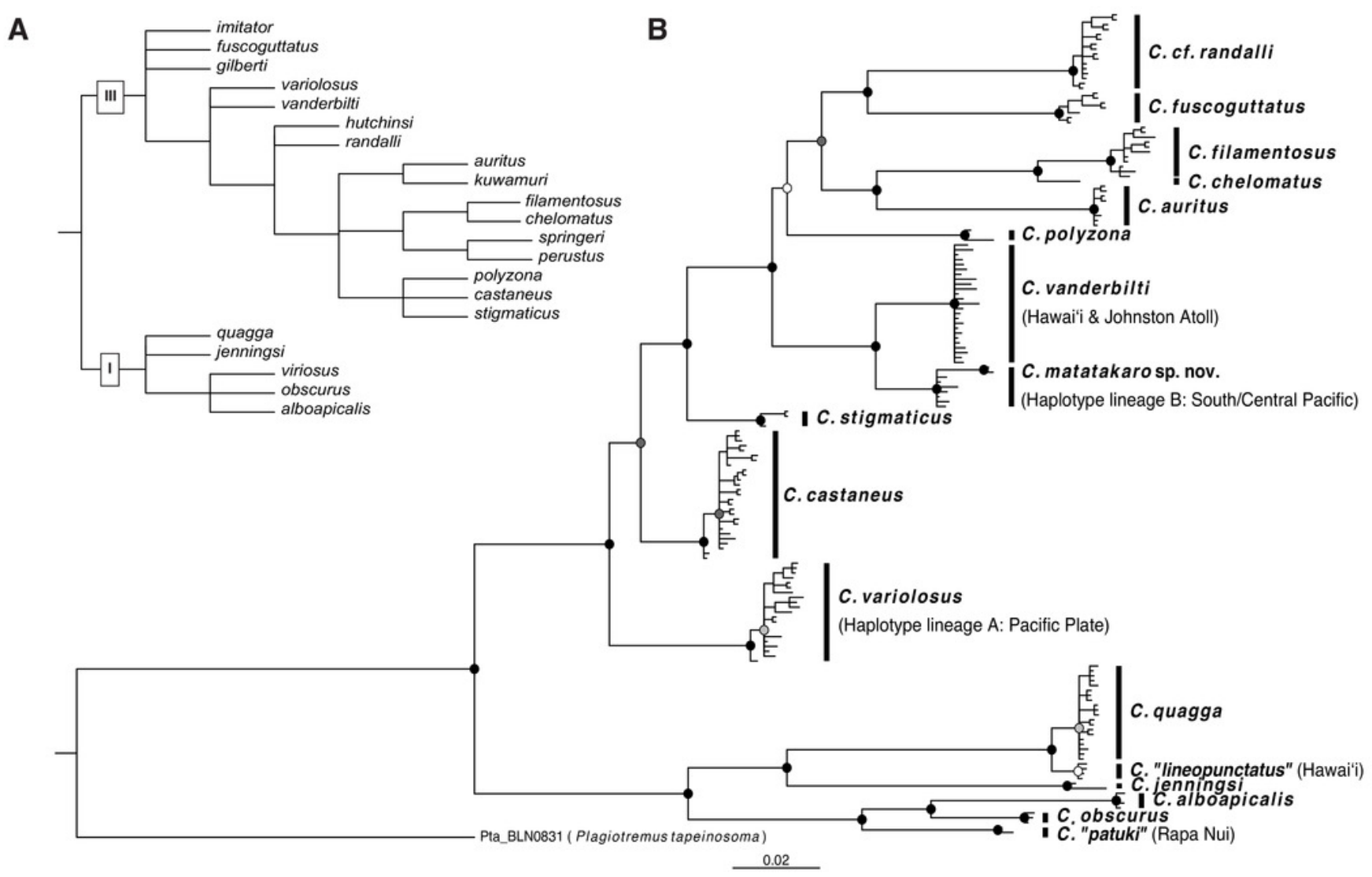




\section{Figure 7}

Photographs of freshly dead Cirripectes matatakaro sp. nov. specimens showing live coloration.

(A) $60 \mathrm{~mm}$ SL adult male holotype (USNM 423364, Austral Islands). (B) $60 \mathrm{~mm}$ SL adult female paratype (USNM 409139, Marquesas Islands). Photographed by Jeffrey T. Williams, Smithsonian Institution.

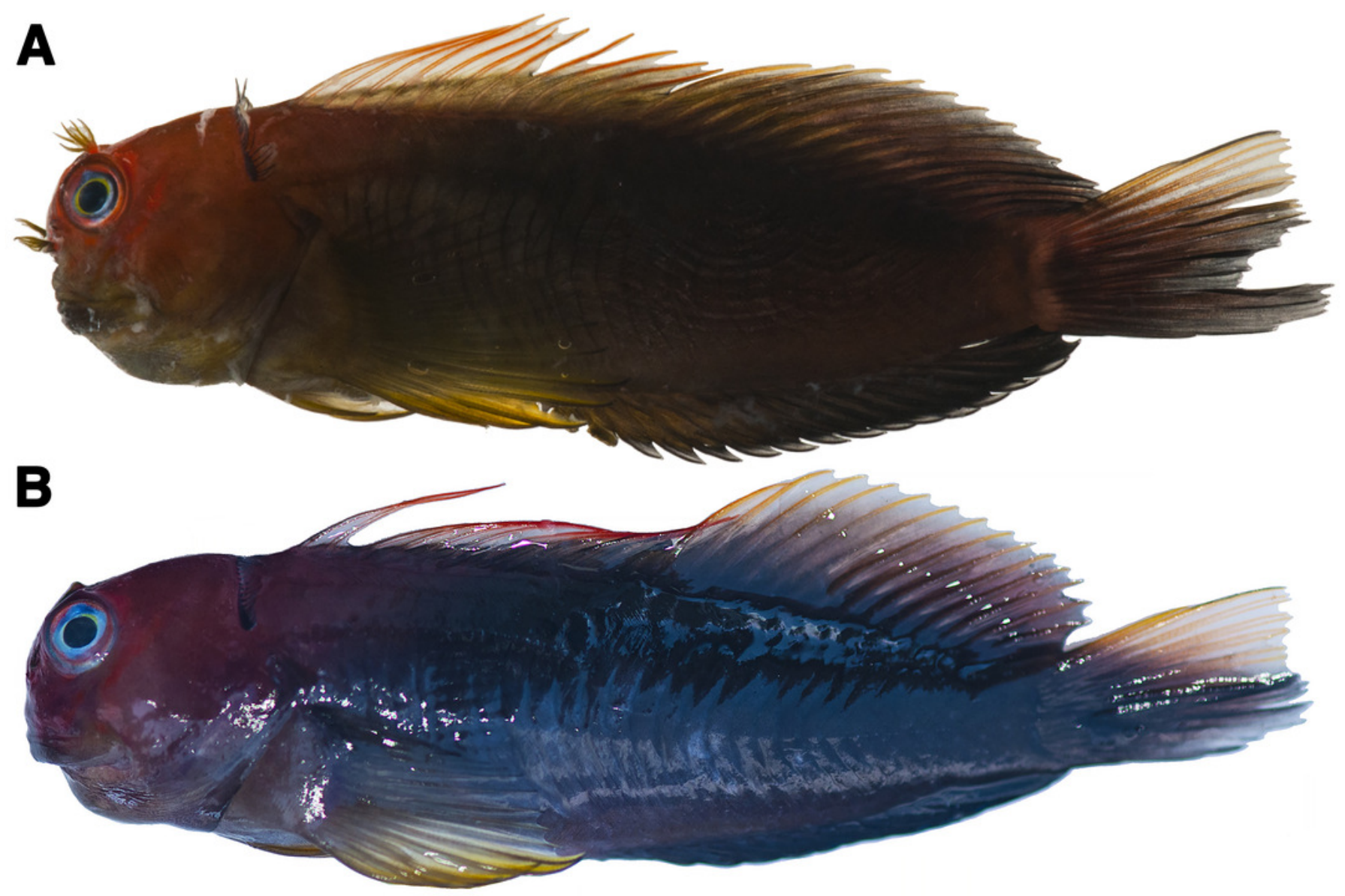




\section{Figure 8}

Freshly dead Cirripectes matatakaro sp. nov. 43mm SL adult male paratype (BPBM 16928, Pitcairn Island).

Photographed by John E. Randall (Smithsonian Institution, 1970).

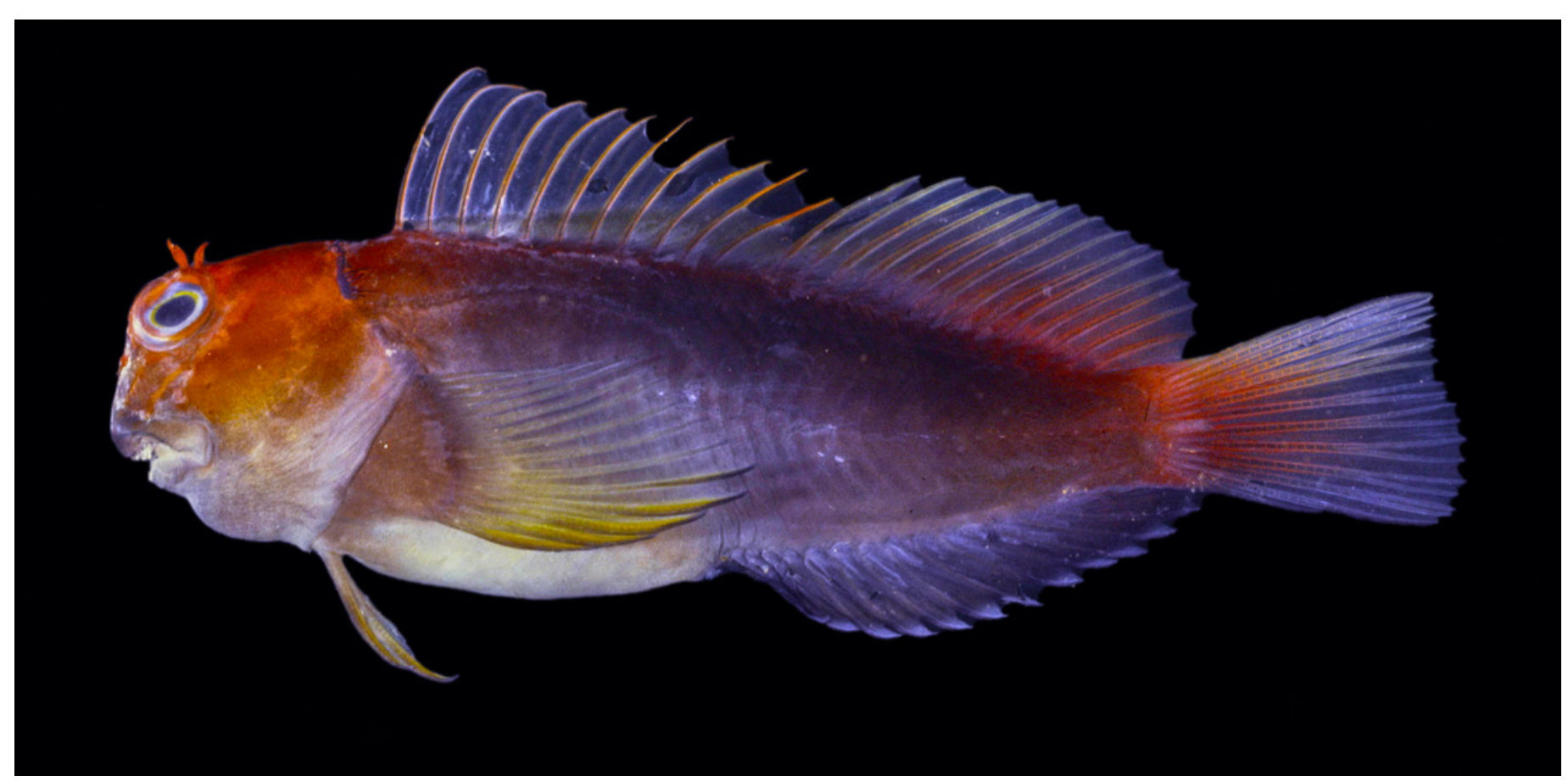




\section{Figure 9}

Radiograph of Cirripectes matatakaro sp. nov. holotype, USNM 423364, 60mm SL, Austral Islands.

\section{$10 \mathrm{~mm}$}




\section{Figure 10}

Underwater photograph of likely female Cirripectes matatakaro sp. nov. Photographed by D. Rolla at Kiritimati Island, Kiribati, Line Islands.

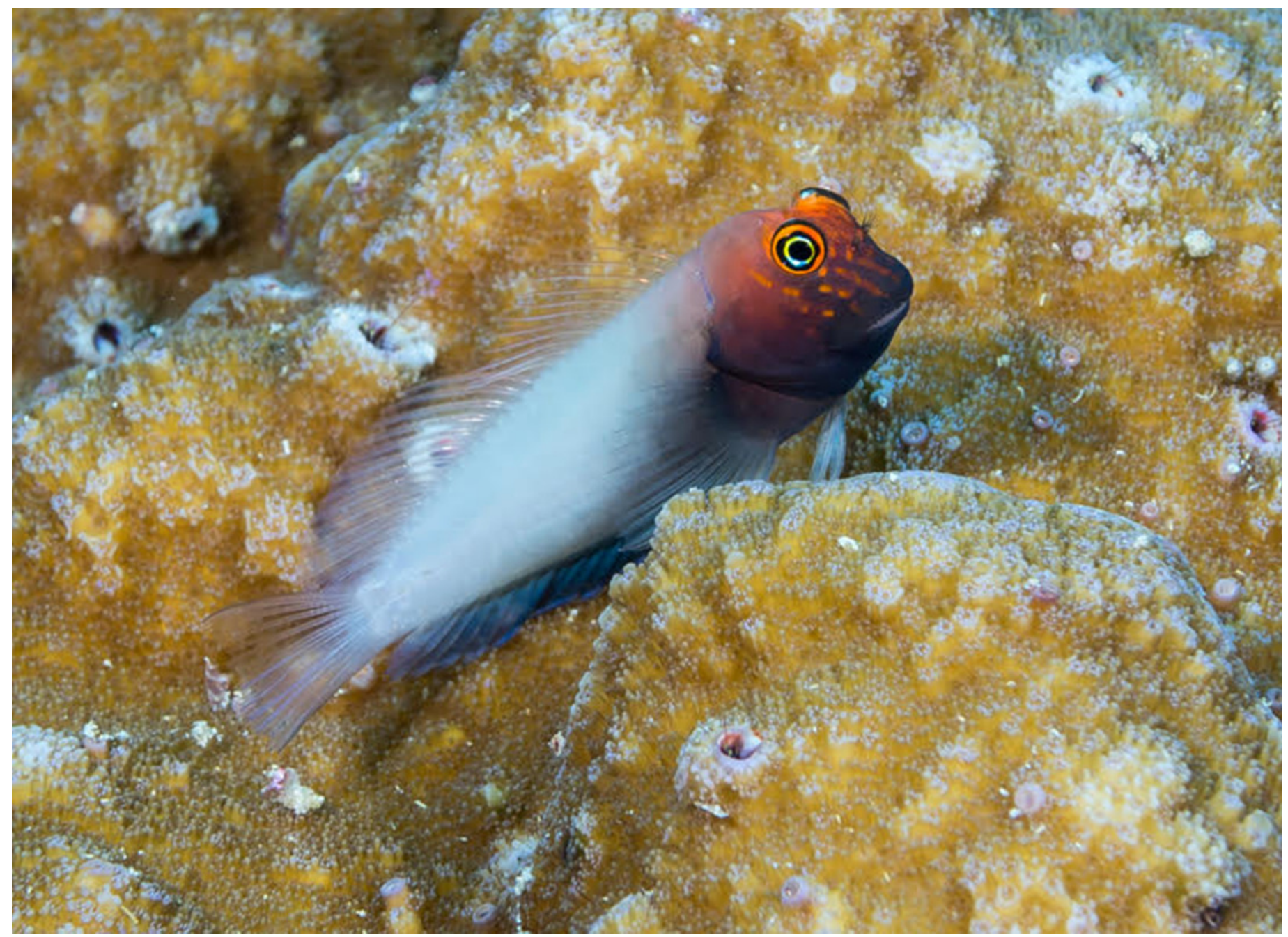


Figure 11

Biplot of the first two principal components from a PCA of 12 meristic characters and 9 morphometric characters of 72 specimens of three Combtooth Blenny species.

Some characters combined or averaged when doubled, characters with zero variance dropped. Maroon axes indicate loading amplitudes and directions. Points represent individual specimens, color coded by nominal species: red: Cirripectes variolosus, blue: $C$. vanderbilti, black: C. matatakaro sp. nov.

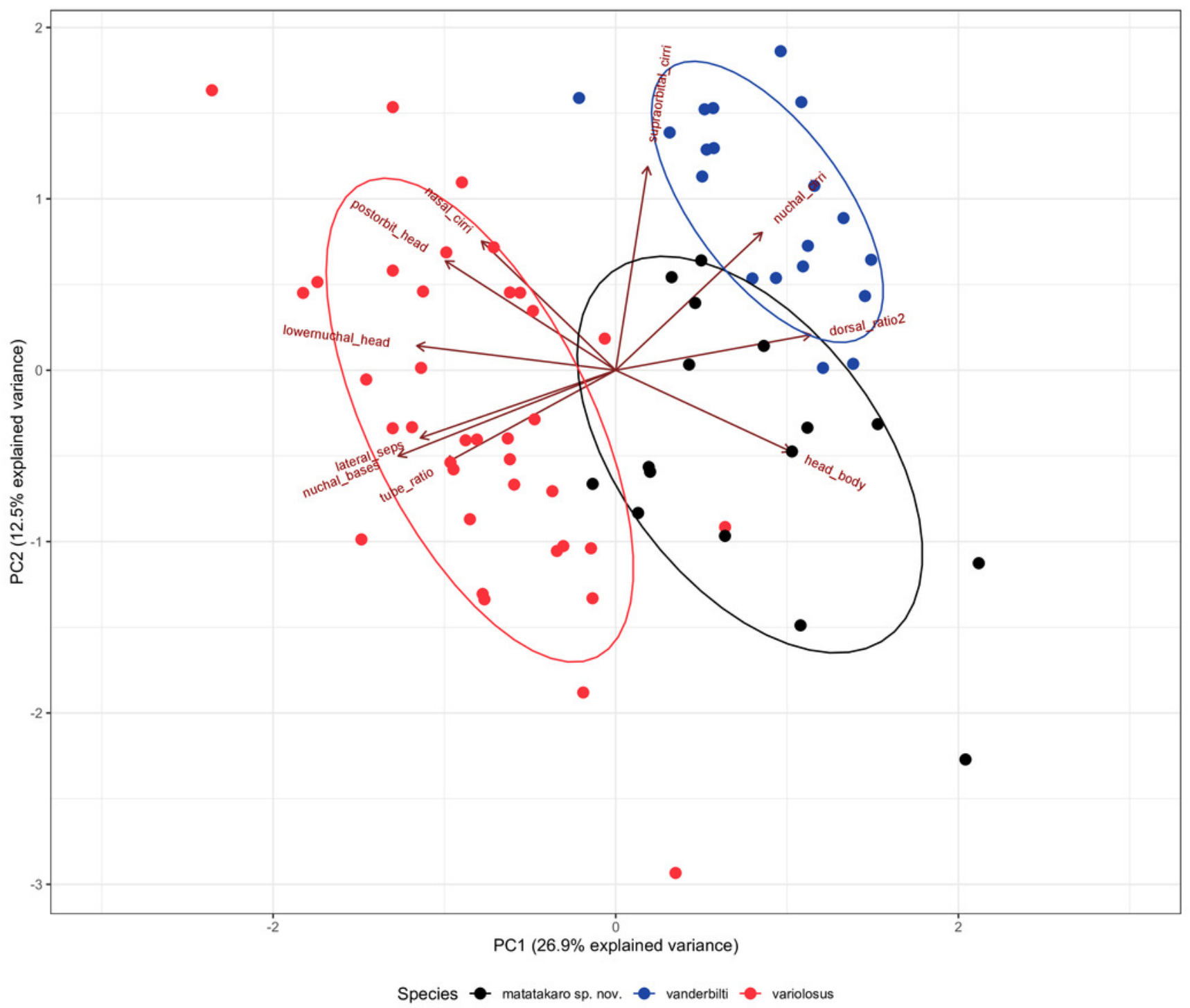


Table $\mathbf{1}$ (on next page)

External sequences used for phylogenetic reconstruction. 
Species

Cirripectes alboapicalis

Cirripectes auritus

Cirripectes castaneus

Cirripectes chelomatus

Cirripectes filamentosus

Cirripectes fuscoguttatus

Cirripectes heemstraorum

Cirripectes jenningsi

Cirripectes obscurus

Cirripectes polyzona

Cirripectes quagga

Cirripectes stigmaticus

Cirripectes variolosus
GenBank Accession Number(s)

MH707846,MH707847

KF489554

JQ349900,JQ349901,JQ349904,JQ349905,

KX301891,MF409520,MF409642

Published in BOLD, not entered in GenBank

(BOLD BIN: BOLD:AAY8754)

KX301893

JQ431645,JQ431646,MH707851,MH707853

GU357568,GU357569

MH707854,MK658251

MH707855

HQ168554

KJ968000,KJ968001,KJ968004,

$\mathrm{MH707862,MH707864,MH707865}$

JQ349909,JQ349910,KF929762,KF929763,

KP194481,KP194898,KP194899,MF409601

KJ968005,KU944801,MH707867-MH707872,

MH707876-MH707881

\section{Sequences}

2

1

7

3

2

4

2

2

1

1

6

11

14 


\section{Table 2 (on next page)}

Morphometric and meristic data for selected characters of type specimens of Cirripectes matatakaro sp. nov.

Measurements given in $\mathrm{mm}$. 
Morphometrics

Sex

Standard length

Head length

Depth at anus

Postorbital-midnuchal distance

Supraorbital cirri length

Nuchal separation, dorsal

Nuchal separation, left

Nuchal separation, right

Lower nuchal to opercle distance

Length of dorsal spine I

Length of dorsal spine II

Length of dorsal spine III

Length of first dorsal ray

Height of dorsal notch

\begin{tabular}{c} 
Holotype \\
\hline USNM \\
$\mathbf{4 2 3 3 6 4}$
\end{tabular}

Male

57.8

16.8

16

7

2.2

0.4

0

0

1.5

8.1

8.6

9

8.2

1.4

\section{Meristics}

Dorsal

Anal

Pectoral

Pelvic

Nuchal cirri

Nasal cirri

Supraorbital cirri

Lateral line tubes

Last tube under dorsal spine

Pseudobranchial filaments

Gill rakers

Upper lip crenulations

1

Paratypes

\begin{tabular}{cccccc}
\hline USNM & USNM & USNM & BPBM & BPBM & CAS \\
409140 & 409139 & $\mathbf{4 0 4 7 0 2}$ & $\mathbf{1 6 9 2 8 ( 1 )}$ & $\mathbf{1 6 9 4 1}(\mathbf{1})$ & $\mathbf{4 8 9 6 5}$ \\
Male & Female & Female & Male & Female & Female \\
41 & 60 & 29.3 & 42.5 & 53 & 64 \\
12.8 & 15.3 & 9.6 & 12.6 & 13.9 & 16.4 \\
11.1 & 16.6 & 4.7 & 11.8 & 12.7 & 16.4 \\
5 & 7.5 & 2.7 & 5.8 & 6.7 & 7.4 \\
0.9 & 1.8 & 0.3 & 1.7 & 1.8 & 2.1 \\
0.3 & 0.1 & 0.3 & 0.3 & 0.3 & 0.2 \\
0 & 0 & 0 & 0 & 0 & 0 \\
0 & 0 & 0 & 0 & 0 & 0 \\
1.1 & 1.6 & 0.9 & 1.6 & 1.8 & 1.9 \\
6.9 & 10.6 & 4.7 & 11.5 & 12.2 & 13.5 \\
4.9 & 10.9 & 5.2 & 10.7 & 11.1 & 14.5 \\
5.3 & 10.9 & 4.9 & 10.5 & 10.5 & 12.8 \\
7.6 & 10 & 5.2 & 9.4 & 11.1 & 11.4 \\
1.3 & 2 & 0.4 & 2.7 & 3.6 & 4.2
\end{tabular}

XII, 14

XII, 14

XII, 14

XII, 14

XII, 14

XII, $14 \quad$ XII, 14

II, 15

II, 15

II, 15

II, 15

II, 15

II, 15

II, 15

15

I, 4

15

15

15

15

15

15

I, $4 \quad$ I, 4

I, 4

I, 4

I, 4

I, 4

34

$5+5$

38

37

32

32

38

35

$4+4$

$4+4$

$4+5$

$5+5$

$7+5$

$6+6$

$4+5$

$4+4$

$4+4$

$5+4$

$5+5$

4

12

3

4

2

$4+5$

$6+5$

$9+9$

10

12

6

2

1

2

n/a $\quad 7+7$

n/a

10

9

10

21

n/a

22

$8+8$

$9+8$

8

49 $\mathrm{n} / \mathrm{a}$

45

23

28

47

27

28

46 